Research Paper

\title{
Calcitriol and non-calcemic vitamin D analogue, 22-oxacalcitriol, attenuate developmental and pathological choroidal vasculature angiogenesis ex vivo and in vivo
}

\author{
Stephanie L. Merrigan', Bomina Park ${ }^{2,3}$, Zaheer Ali ${ }^{4}$, Lasse D. Jensen ${ }^{4}$, Timothy \\ W. Corson ${ }^{2,3}$ and Breandán N. Kennedy ${ }^{1}$ \\ ${ }^{1}$ UCD School of Biomolecular and Biomedical Science, UCD Conway Institute, University College Dublin, Dublin D04 V1W8, \\ Ireland \\ ${ }^{2}$ Eugene and Marilyn Glick Eye Institute, Department of Ophthalmology, Indiana University School of Medicine, Indianapolis, \\ Indiana, USA \\ ${ }^{3}$ Department of Pharmacology and Toxicology, Indiana University School of Medicine, Indianapolis, Indiana, USA \\ ${ }^{4}$ Division of Cardiovascular Medicine, Department of Medical and Health Sciences, Linköping University, Linköping, Sweden \\ Correspondence to: Breandán N. Kennedy, email: brendan.kennedy@ucd.ie
}

Keywords: developmental angiogenesis; pathological angiogenesis; ocular angiogenesis; calcitriol; 22-oxacalcitriol

Received: July 22, $2019 \quad$ Accepted: October 19, $2019 \quad$ Published: February 04, 2020

Copyright: Merrigan et al. This is an open-access article distributed under the terms of the Creative Commons Attribution License 3.0 (CC BY 3.0), which permits unrestricted use, distribution, and reproduction in any medium, provided the original author and source are credited.

\section{ABSTRACT}

Aberrant ocular angiogenesis can underpin vision loss in leading causes of blindness, including neovascular age-related macular degeneration and proliferative diabetic retinopathy. Current pharmacological interventions require repeated invasive administrations, may lack efficacy and are associated with poor patient compliance and tachyphylaxis. Vitamin D has de novo anti-angiogenic properties. Here, our aim was to validate the ocular anti-angiogenic activity of biologically active vitamin $\mathrm{D}$, calcitriol, and selected vitamin D analogue, 22-oxacalcitriol. Calcitriol induced a significant reduction in ex vivo mouse choroidal fragment sprouting. Viability studies in a human RPE cell line suggested non-calcemic vitamin $D$ analogues including 22-oxacalcitriol have less offtarget anti-proliferative activity compared to calcitriol and other analogues. Thereafter, the anti-angiogenic activity of 22-oxacalcitriol was demonstrated in an ex vivo mouse choroidal fragment sprouting assay. In zebrafish larvae, 22-oxacalcitriol was found to be anti-angiogenic, inducing a dose-dependent reduction in choriocapillaris development. Subcutaneously administered calcitriol failed to attenuate mouse retinal vasculature development. However, calcitriol and 22-oxacalcitriol administered intraperitoneally, significantly attenuated lesion volume in the laser-induced choroidal neovascularisation mouse model. In summary, calcitriol and 22-oxacalcitriol attenuate ex vivo and in vivo choroidal vasculature angiogenesis. Therefore, vitamin $\mathbf{D}$ may have potential as an interventional treatment for ophthalmic neovascular indications.

\section{INTRODUCTION}

Pathological neovascularisation of ocular blood vessels can promote vision loss in leading causes of blindness including neovascular age-related macular degeneration (nAMD) and proliferative diabetic retinopathy. Worldwide, $8.7 \%$ of blindness results from AMD. nAMD accounts for only $10 \%$ of AMD cases but greater than $80 \%$ of poor visual acuity cases [1-4]. Rapid vision loss in nAMD is driven by pathological choroidal vasculature angiogenesis. This pathological vasculature can be deficient in tight junctions, leak plasma or blood, cause scarring, project through the Bruch's membrane, cause retinal pigmented epithelium (RPE) detachment and disrupt normal perfusion of the retina [5-7]. Worldwide 382 million people suffer from 
diabetes, approximately $35 \%$ of whom develop diabetic retinopathy, making this the leading cause of blindness in the working age population [8]. Severe vision loss is a consequence of macular oedema and sprouting of poorly formed retinal vessels into the vitreous [8]. This retinal neovascularisation can result in haemorrhaging and retinal detachment [9].

Endogenous pro-angiogenic factors including vascular endothelial growth factor (VEGF), angiopoietins (ang-1, ang-2), platelet-derived growth factors (PDGF-A, PDGF-B) and transforming growth factor (TGF- $\beta$ ), plus their cognate receptors, promote normal vasculature development [6]. After development, a tightly regulated balance of pro- and anti-angiogenic factors maintain the mature quiescent vasculature. Pathological insults such as hypoxia can disrupt this equilibrium and promote neovascularisation $[10,11]$. VEGF is a pivotal regulator of ocular and tumour angiogenesis, clinically evident from the success of anti-VEGF targeting therapies. Ranibizumab (Lucentis ${ }^{\circledR}$ ), bevacizumab (Avastin ${ }^{\circledR}$ ) and aflibercept $\left(\right.$ Eylea $\left.^{\circledR}\right)$ are utilised in the treatment of ocular neovascularisation [12]. These anti-VEGF therapies cause vessel regression and improve visual function [3]. Despite representing the standard of care, several treatment limitations exist. Firstly, with molecular weights between 50-149 $\mathrm{kDa}$, current interventions require administration by intravitreal injection [13]. This places a burden both on patients and clinicians which can result in inadequate dosing, exemplified by the CATT/IVAN trial, where an average of 4-5 treatments were administered compared to the recommended 7-8 [7]. Secondly, repeated administrations are required. Aflibercept has the greatest intravitreal half-life of the anti-VEGF therapies yet treatments are required every 2 months $[3,14]$. In addition, continuous long-term antiVEGF therapy is required, and cessation of treatment can result in reoccurrence of neovascularisation [15].Thirdly, anti-VEGF therapies are associated with a severe economic burden, with aflibercept costing approximately $€ 1,000$ per injection [16]. Finally, anti-VEGF therapy can lack efficacy in non-responsive populations and tachyphylaxis can occur. A non-responsive population of $45 \%$ is reported with bevacizumab [17]. Tachyphylaxis is postulated to be a consequence of compensatory VEGF upregulation or generation of neutralising antibodies [14]. These limitations highlight the need to identify and develop safe, efficacious, cost effective anti-angiogenics with a less invasive route of administration.

Vitamin D is a fat-soluble steroid hormone with pleiotropic health implications. Recognised as having pro-differentiative, anti-proliferative, immunomodulatory, pro-apoptotic and anti-angiogenic properties; vitamin $\mathrm{D}$ is under examination for malignant, cardiovascular, cognitive, metabolic, infectious and autoimmune disorders [18-20]. Vitamin D has the potential to prevent and/or treat cancer and a proposed mechanism is through inhibition of angiogenesis required for tumour growth [21]. Interestingly, the vitamin D receptor (VDR) is expressed in the cornea, lens, ciliary body, RPE, ganglion cell layer and photoreceptors, supporting ocular functions [22]. In 2017, we reported the biologically active form of vitamin D, calcitriol, and diverse VDR agonists including vitamin $\mathrm{D}_{2}$ analogues, vitamin $\mathrm{D}_{3}$ analogues and a pro-hormone to attenuate in vivo ocular vasculature development in zebrafish [23]. Further interrogation of the anti-angiogenic activity was needed in ocular mammalian models to assess the therapeutic potential of vitamin D.

Here, we examined the anti-angiogenic activity of calcitriol and 22-oxacalcitriol in in vitro, ex vivo or in vivo vasculature systems. Calcitriol and 22-oxacalcitriol significantly inhibit ex vivo mouse choroidal sprouting angiogenesis, yet in a simpler, non-ocular in vitro cord formation assay, anti-angiogenic activity was not identified. With increased model complexity calcitriol and 22-oxacalcitriol again induced antiangiogenic responses, showing reduced developmental angiogenesis in a zebrafish larval model and/or attenuated neovascularisation in a pathological mouse model which recapitulates features of nAMD. Drug safety was assessed through animal weight monitoring, and 22-oxacalcitriol presented with a safer profile compared to calcitriol. Here, our studies support further pre-clinical investigations into non-calcemic vitamin D analogue, 22-oxacalcitriol, for the treatment or prevention of choroidal neovascularisation.

\section{RESULTS}

\section{Calcitriol attenuates mouse ex vivo choroid-RPE fragment sprouting angiogenesis}

Previously, we demonstrated calcitriol and seven other VDR agonists to inhibit ocular vasculature development in zebrafish larvae [23]. To identify the most active antiangiogenic VDR agonist in mammalian models, the cord formation assay, a late stage in vitro angiogenesis model, was performed. Human dermal-derived microvascular endothelial cells, HMEC-1 cells, were seeded in a matrix and cultured with $10 \mu \mathrm{M}$ calcitriol, 22-oxacalcitriol, tacalcitol or vehicle control and cord formation quantified after $16 \mathrm{~h}$. The Angiogenesis Analyzer for ImageJ was utilised for automatic unbiased measurement of cord formation properties. Surprisingly, VDR agonist-treated HMEC-1 cells exhibited no significant difference in cord formation compared to vehicle controls (Supplementary Figure 1A1B). Cord formation properties are influenced by cell type (primary or immortalised), derivation (human or non-human) and tissue origin [24]. With ocular selective anti-angiogenic activity previously identified in zebrafish larvae, cord formation was also investigated in human 
retinal-derived microvascular endothelial cells (HREC). HREC cells were seeded in a matrix and cultured with $10 \mu \mathrm{M}$ calcitriol for $16 \mathrm{~h}$. Again, no significant cord formation difference was identified between vehicle control and calcitriol treated HREC cells (Supplementary Figure 1C-1D).

To investigate the anti-angiogenic activity of calcitriol in a more physiologically relevant model, the ex vivo mouse choroidal sprouting angiogenesis assay was employed (Figure 1A). This system is multicellular in nature and accounts for micro-environmental cues which support angiogenesis [25]. Calcitriol treatments between 5-10 $\mu \mathrm{M}$ significantly $(\mathrm{p}<0.001)$ reduced choroidal sprouting area by up to $93 \%$ compared to vehicle control. No significant difference in sprouting was identified with $1 \mu \mathrm{M}$ calcitriol treatments (Figure 1B-1D). Calcein staining confirmed explant and sprout viability after 1-10 $\mu \mathrm{M}$ treatments (Figure 1D).

\section{Calcitriol attenuates RPE cell viability, while non-calcemic vitamin $D_{3}$ analogues show a greater RPE cell safety profile}

Pro-apoptotic and anti-proliferative properties of calcitriol are known [26]. Such actions on endothelial cells could underpin the anti-angiogenic mechanism of calcitriol. However, induction of apoptosis is undesirable in neighbouring cells such as the RPE. Thus, we sought to identify VDR agonists with negligible effects on RPE cell viability. VDR agonist-induced changes in ARPE-19 cell number were determined by the surrogate measure of metabolic activity, quantified using the MTT assay. Calcitriol was tolerated over $24 \mathrm{~h}$ in ARPE-19 cells, with no significant change in cell viability with concentrations $\leq 20 \mu \mathrm{M}$ (Figure 2A). However, treatments with $\geq 10 \mu \mathrm{M}$ calcitriol for $48 \mathrm{~h}$ significantly reduced ARPE-19 cell viability in a concentration-dependent manner, $10 \mu \mathrm{M}$ $(\mathrm{p} \leq 0.05), 15 \mu \mathrm{M}(\mathrm{p} \leq 0.01)$ and $20 \mu \mathrm{M}(\mathrm{p} \leq 0.001)$ (Figure 2B). Cell viability in response to a range of VDR agonist treatments were subsequently investigated in ARPE-19 cells, over $96 \mathrm{~h}$. Vitamin $\mathrm{D}_{2}$ analogue, doxercalciferol, reduced ARPE-19 cell viability $(\sim 42 \%)$ with $10 \mu \mathrm{M}$ treatment $(\mathrm{p} \leq 0.01)$ (Figure $2 \mathrm{C})$. Vitamin $\mathrm{D}_{2}$ analogue, paricalcitol, had no significant effect on ARPE-19 cell viability with treatments $\leq 10 \mu \mathrm{M}$ (Figure 2D). Vitamin $\mathrm{D}_{3}$ analogues, tacalcitol and calcipotriol, induced a significant reduction ( $\sim 2$ and 29\%, respectively) in ARPE-19 cell viability with concentrations $\geq 5 \mu \mathrm{M}$ (Figure $2 \mathrm{E}-\mathrm{F}$ ). Noncalcemic vitamin $\mathrm{D}_{3}$ analogues were better tolerated. No significant change in ARPE-19 cell viability was identified with 22-oxacalcitriol or EB 1089 treatments $\leq 10$ $\mu \mathrm{M}$ (Figure 2G-H). Therefore, non-calcemic vitamin $\mathrm{D}_{3}$ analogue, 22-oxacalcitriol, was selected for further investigation. Notably, further safety studies investigating the effects of non-calcemic vitamin $\mathrm{D}_{3}$ analogues in vivo are required, as a trend of reduced viability in vitro, although not significant, was demonstrated here. Finally, vitamin $\mathrm{D}_{3}$ pro-hormone, calcifediol, significantly attenuated ARPE-19 cell viability by up to $45 \%$ with concentrations $\geq 5 \mu \mathrm{M}(\mathrm{p} \leq 0.001)$ (Figure $2 \mathrm{I})$.

\section{Non-calcemic vitamin $D_{3}$ analogue 22-oxacalcitriol inhibits mouse ex vivo choroidal sprouting angiogenesis}

To investigate the anti-angiogenic activity of 22-oxacalcitriol, the ex vivo choroidal sprouting angiogenesis assay was performed. $10 \mu \mathrm{M}$ 22-oxacalcitriol significantly attenuated mouse ex vivo choroid-RPE fragment sprouting angiogenesis by up to $42 \%(\mathrm{p} \leq 0.05)$ (Figure 3A-3C). In addition, calcein staining confirmed explant and sprout viability after treatment (Figure 3C).

\section{Non-calcemic vitamin $D_{3}$ analogue 22-oxacalcitriol inhibits zebrafish choriocapillaris development}

In zebrafish, the choriocapillaris starts developing by 24 hours post fertilisation (hpf) and becomes a perfused vascular network by $72 \mathrm{hpf}$. We treated zebrafish with ascending concentrations of 22-oxacalcitriol, between 24 and $72 \mathrm{hpf}$, and evaluated the effects on choriocapillaris development (Figure 4A). Using the number of interstitial pillars (ISPs) as a measure of angiogenic activity, the development of the choriocapillaris was markedly inhibited by 22-oxacalcitriol in a concentration-dependent manner. While $0.1 \mu \mathrm{M}$ did not lead to reduced ISP formation compared to controls, treatment with 1 or 10 $\mu \mathrm{M} 22$-oxacalcitriol led to a moderate reduction to $80.1 \%$ $( \pm 4.6)$ and $79.5 \%( \pm 3.2)$ respectively of the ISPs found in control DMSO-treated eyes (Figure 4B-4C). Importantly, treatment with 22-oxacalcitriol distorted the characteristic lobular vascular pattern of the choriocapillaris (Figure 4C). These findings clearly indicate that 22-oxacalcitriol inhibits choriocapillaris development in zebrafish.

\section{Subcutaneous calcitriol treatment does not adversely affect adult mouse retinal structures or superficial retinal vasculature development}

Prior to in vivo assessment of the anti-angiogenic activity of calcitriol, ocular safety was evaluated in adult $\mathrm{C} 57 \mathrm{BL} / 6 \mathrm{~J}$ mice. Adult mice received a single 50 ng subcutaneous calcitriol or vehicle control treatment, and retinal histology was investigated 7 days later. Vehicle controls and calcitriol treated mice presented with animal welfare scores comparable to un-injected mice, with mouse weight recorded daily (Figure 5B). On day 7 , mice were euthanised, eyes enucleated, fixed and sectioned. Ultra-thin toluidine blue stained cross sections were investigated for the presence of pyknotic nuclei 


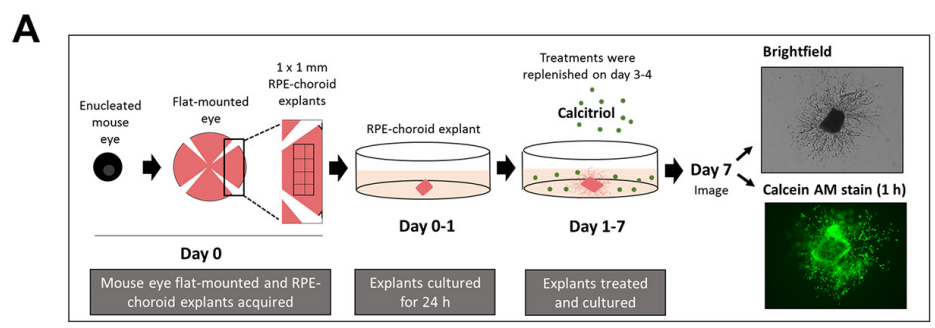

B
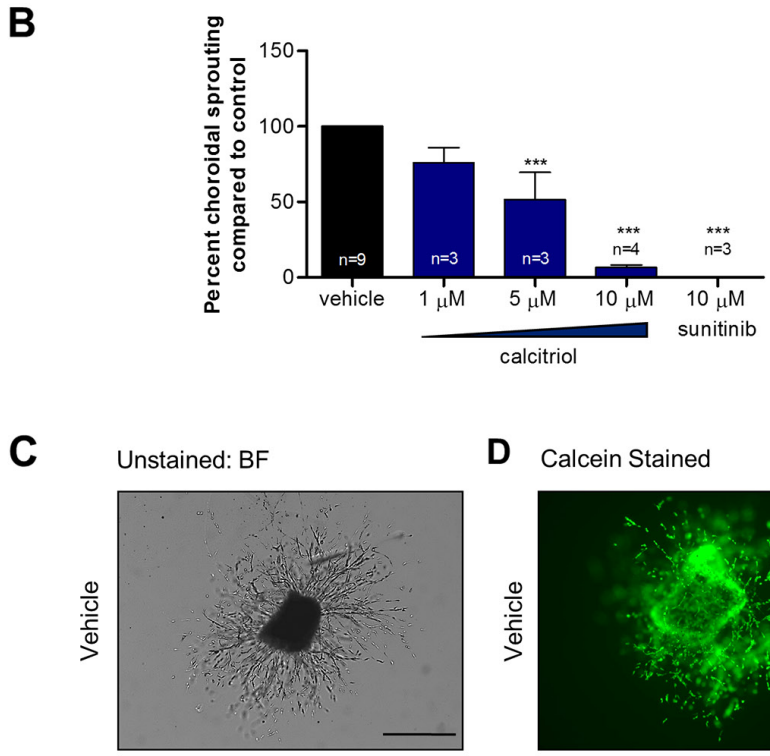

D Calcein Stained
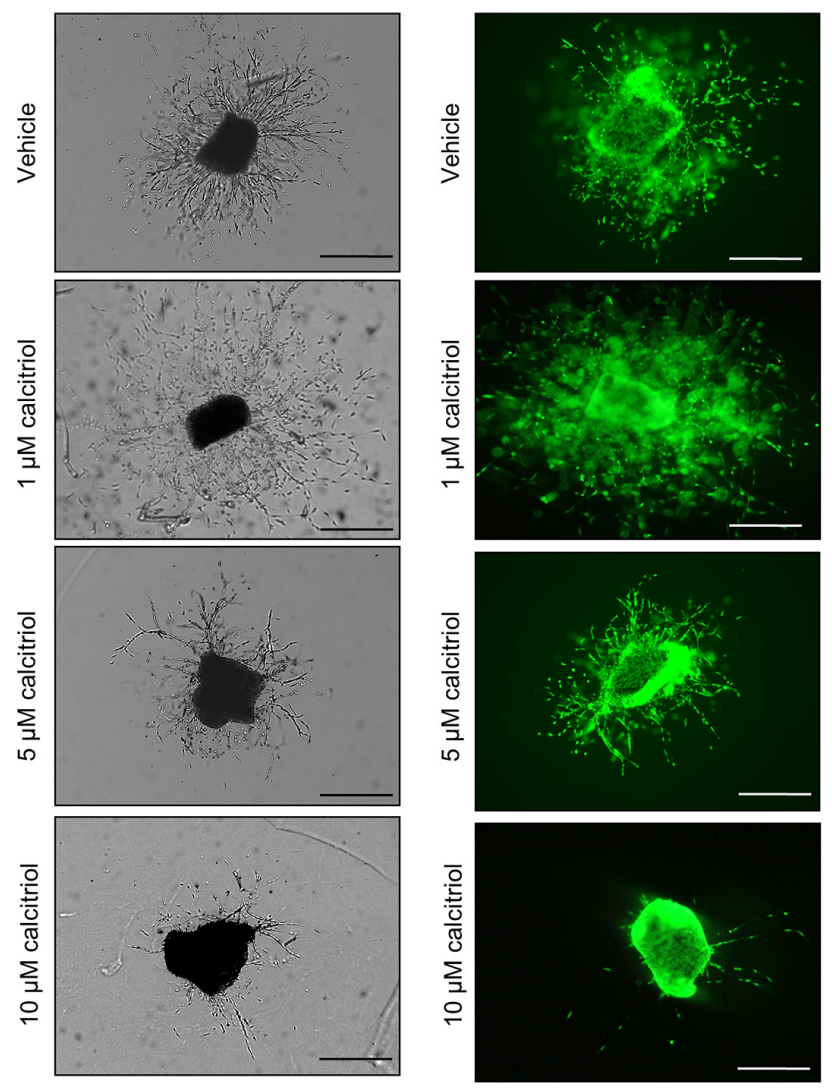

Figure 1: Calcitriol attenuates mouse choroidal sprouting angiogenesis. (A) Mouse RPE-choroidal fragments were cultured in Matrige $\mathrm{l}^{\circledR}$ for $24 \mathrm{~h}$ and further cultured with indicated drug treatments for 6 days. On day 7, samples were fixed and sprouting area quantified from phase contrast images using ImageJ freehand tool. (B) Calcitriol 5-10 $\mu \mathrm{M}$ or $10 \mu \mathrm{M}$ sunitinib positive control significantly attenuated choroidal sprouting angiogenesis. Graph shows mean percent sprouting area compared to vehicle control \pm SEM; statistical analyses were performed using one-way ANOVA with Dunnett's post hoc test, asterisk indicates ${ }^{* * *} \mathrm{p} \leq 0.001$ and $\mathrm{n}$ as indicated with up to 6 replicates per individual experiment. (C) Representative brightfield images of mouse choroidal sprouting after 7 days with indicated treatments. (D) Calcein stained representative images of mouse choroidal sprouting after 7 days with indicated treatments. Calcein staining of RPE-choroidal cultures confirms explant viability in vehicle and calcitriol treated explants. Scale bar represents $0.5 \mathrm{~mm}$. 
and deviations in the highly organised cell lamination of the eye. Calcitriol treatments appeared well tolerated in mice, with no observable difference between vehicle and calcitriol treated retinal structures (Figure 5A).

Retinal vasculature development after birth in mice provides a unique opportunity to study developmental angiogenesis. Normal mouse retinal vasculature growth is well documented, and drugs can inhibit this growth [27-29].
Calcitriol attenuates zebrafish ocular developmental angiogenesis, therefore, we sought to investigate if this response translated to the mouse. To validate the model, the anti-angiogenic activity of positive control, rapamycin, was evaluated. C57BL/6J mouse pups were injected subcutaneously with $10 \mathrm{mg} / \mathrm{kg}$ rapamycin or vehicle control at postnatal day 1 (P1), welfare monitored daily and superficial retinal vasculature

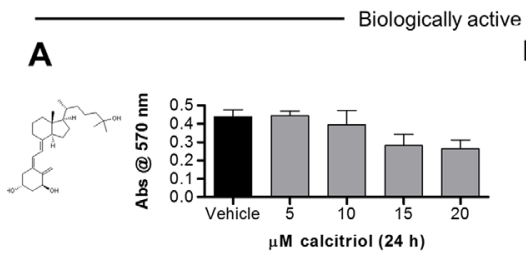

B

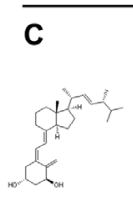

Vitamin $\mathrm{D}_{2}$ analogues

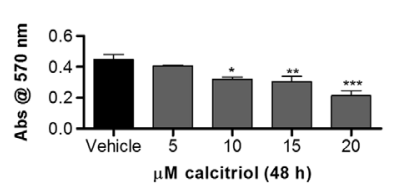

D
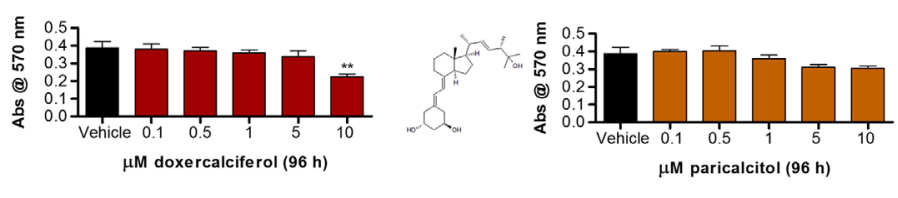

$\mu \mathrm{M}$ paricalcitol $(96 \mathrm{~h})$

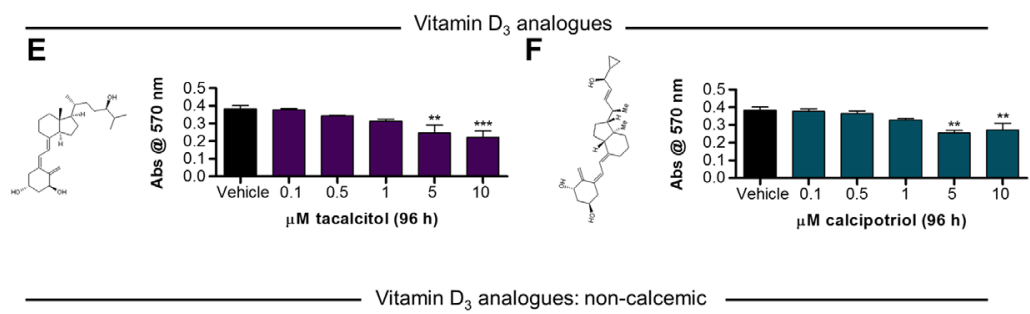

G

$\mathbf{H}$
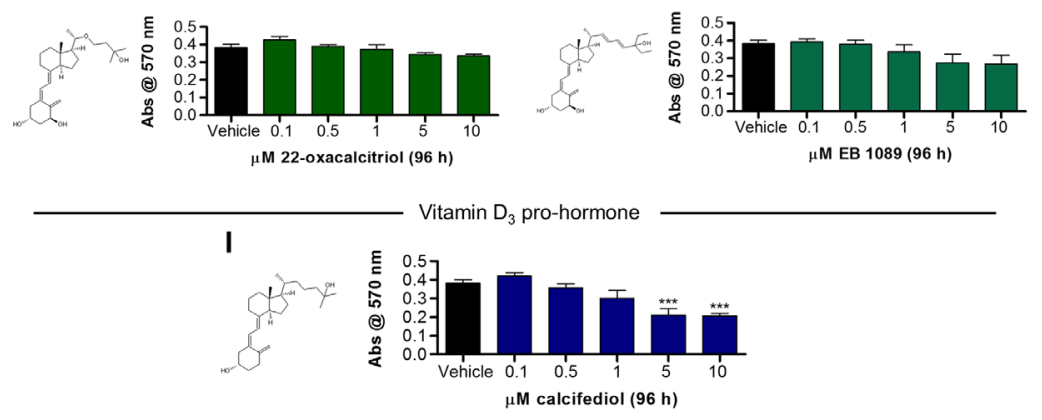

Figure 2: Vitamin D analogues attenuate ARPE-19 cell viability in a and concentration-dependent manner. (A-B) Serum starved ARPE-19 cells were cultured with 5-20 $\mu \mathrm{M}$ calcitriol for $24 \mathrm{~h}$ or $48 \mathrm{~h}$ and cell viability assessed by MTT assay. No significant difference in cell metabolic activity with $24 \mathrm{~h}$ calcitriol treatment was found. Calcitriol treatments $(10-20 \mu \mathrm{M})$ for $48 \mathrm{~h}$ significantly reduced cell metabolic activity. (C-I) Serum starved ARPE-19 cells were cultured with 0.1-10 $\mu \mathrm{M}$ vitamin $\mathrm{D}_{2}$ analogues, vitamin $\mathrm{D}_{3}$ analogues, non-calcemic vitamin $\mathrm{D}_{3}$ analogues, vitamin $\mathrm{D}_{3}$ pro-hormone or vehicle control for $96 \mathrm{~h}$ and cell viability assessed by MTT assay. (C-D) Graphs show mean absorbance at $570 \mathrm{~nm}$ in response to vitamin $\mathrm{D}_{2}$ analogue treatment. (C) ARPE-19 cell viability was attenuated by 10 $\mu \mathrm{M}$ doxercalciferol treatment. (D) No significant change in ARPE-19 cell viability was identified with 0.1-10 $\mu \mathrm{M}$ paricalcitol treatment. (E-F) Graphs show mean absorbance at $570 \mathrm{~nm}$ in response to vitamin $\mathrm{D}_{3}$ analogue treatment. (E) ARPE-19 cell viability was attenuated by 5-10 $\mu \mathrm{M}$ tacalcitol treatment. (F) ARPE-19 cell viability was attenuated by 5-10 $\mu \mathrm{M}$ calcipotriol treatment. (G-H) Graphs show mean absorbance at $570 \mathrm{~nm}$ in response to non-calcemic vitamin $\mathrm{D}_{3}$ analogue treatment. No significant change in ARPE-19 cell viability was identified with $0.1-10 \mu \mathrm{M}$ 22-oxacalcitriol or EB 1089 treatment. (I) Graph show mean absorbance at $570 \mathrm{~nm}$ in response to vitamin $\mathrm{D}_{3}$ pro-hormone, calcifediol. ARPE-19 cell viability was attenuated by 5-10 $\mu \mathrm{M}$ calcifediol treatment. Graphs show mean absorbance at 570 $\mathrm{nm} \pm \mathrm{SEM}$; statistical analysis by one-way ANOVA with Dunnett's post-hoc test compared to vehicle control; asterisk signifies * $\mathrm{p} \leq 0.05$, ${ }^{* *} \mathrm{p} \leq 0.01$ and ${ }^{* * *} \mathrm{p} \leq 0.001$ and group size is $\mathrm{n}=3$, with 4 replicates per $\mathrm{n}$. 
development quantified at P4 (Supplementary Figure 2). No significant difference in mouse weight gain was identified between rapamycin and vehicle treated animals at P1 or P4 (Supplementary Figure 2A). Rapamycin treated mice presented with reduced superficial retinal vasculature area compared to vehicle control treated mice (Supplementary Figure 2B).

Initial studies showed a single calcitriol injection was insufficient to induce an anti-angiogenic response in this model. C57BL/6J mice pups were injected with
3.75 ng subcutaneous calcitriol or vehicle control at P1, welfare monitored daily and superficial retinal vasculature development quantified (Supplementary Figure 3). No significant difference in superficial retinal vasculature area between calcitriol and vehicle control administered mice was identified at P4 (Supplementary Figure 3A \& 3C) or P8 (Supplementary Figure 3B \& 3C). A subsequent study performed subcutaneous calcitriol and vehicle control administration on P1, P3, P5 and P7. Mice pups presented with no welfare concerns and weight gain was comparable

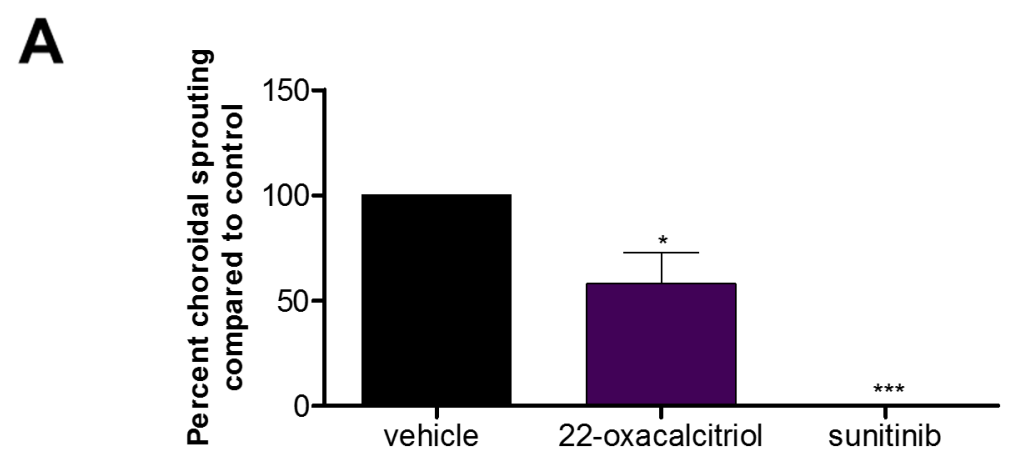

B
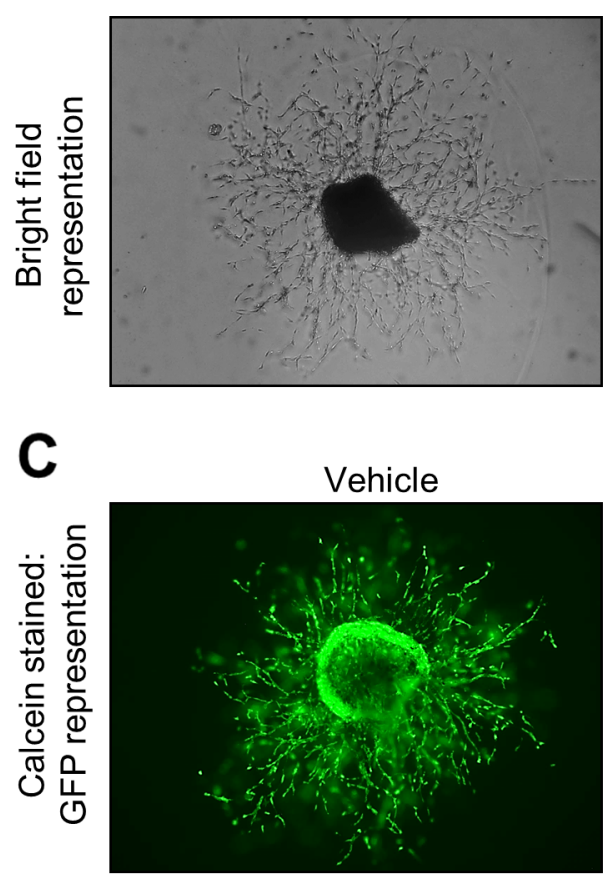

22-oxacalcitriol
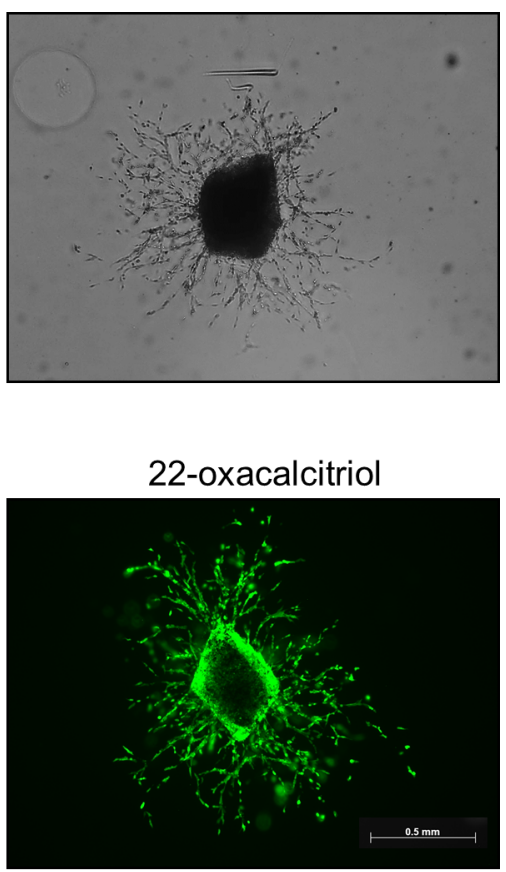

Figure 3: Vitamin $D_{3}$ analogue attenuates mouse choroidal sprouting angiogenesis. Mouse RPE-choroidal fragments were cultured in Matrige $\mathrm{l}^{\mathbb{R}}$ for $24 \mathrm{~h}$ and further cultured with $10 \mu \mathrm{M}$ 22-oxacalcitriol for 6 days. On day 7, samples were fixed and sprouting area quantified from phase contrast images using ImageJ freehand tool. (A) 22-oxacalcitriol and positive control sunitinib significantly attenuated choroidal sprouting angiogenesis. Graph showing mean percent sprouting area compared to vehicle control \pm SEM; statistical analyses were performed using one-way ANOVA with Dunnett's post hoc test; asterisk indicates " $\mathrm{p} \leq 0.05$ and ${ }^{* * *} \mathrm{p} \leq 0.001$ and $\mathrm{n}=3$ with up to 6 replicates per individual experiment. (B) Representative brightfield images of mouse choroidal sprouting after 7 days with indicated treatments. (C) Representative calcein stained images of mouse choroidal sprouting after 7 days with indicated treatments. Calcein staining of RPE-choroidal cultures confirms explant viability in vehicle and 22-oxacalcitriol treated explants. Scale bar represents $0.5 \mathrm{~mm}$. 
in vehicle control and calcitriol treated mice on $\mathrm{P} 4$ or $\mathrm{P} 8$ (Figure 5C). Again, no significant difference in superficial retinal vasculature development between calcitriol and vehicle control treated mice was identified at P4 or P8 (Figure 5D-F).

\section{2-oxacalcitriol inhibits mouse laser-induced choroidal neovascularisation without adverse effects}

Previously calcitriol was reported to reduce retinal neovascularization in the mouse oxygen induced retinopathy (OIR) model of retinopathy of prematurity [30]. To extend upon this finding, we evaluated the effect of calcitriol in the laser-induced choroidal neovascularisation model (L-CNV). To visualize L-CNV and consequential vascular leakage, in vivo optical coherence tomography (OCT) imaging and fluorescein angiography (FA) were performed. Choroidal neovascularisation was inhibited by calcitriol ( $5 \mu \mathrm{g} / \mathrm{kg} /$ day) administered intraperitoneally (Figure 6A-C) and FA revealed vascular leakage of CNV lesions was reduced in calcitriol treated mice (Figure 6B). However, calcitriol treatment had adverse effects on body weight (Figure 6D), perhaps due to hypercalcemiainduced toxicity [31].
Therefore, we sought to evaluate the effect of 22-oxacalcitriol, the non-calcemic bioactive analogue of calcitriol [32]. Notably, 22-oxacalcitriol (15 $\mu \mathrm{g} / \mathrm{kg} /$ day) administered intraperitoneally inhibited vascular leakage and CNV lesion volume assessed based on OCT images (Figure 7A-7C) without any adverse effect on body weight (Figure 7D). CNV was also assessed immunohistochemically by staining vasculature using agglutinin and isolectin GS-IB4. CNV lesion volumes were reduced by $25-30 \%$ upon 22-oxacalcitriol treatment (Figure 7F-H). QRT-PCR identified no significant difference between ocular Vegfa expression in mice treated with 22-oxacalcitriol or vehicle control (Figure 7E).

In summary, calcitriol and 22-oxacalcitriol attenuate mouse ex vivo choroidal vasculature sprouting, 22-oxacalcitriol reduces choriocapillaris development in zebrafish larvae and both calcitriol and 22-oxacalcitriol inhibit choroidal neovascularisation in a mouse model with features of nAMD.

\section{DISCUSSION}

The ocular vasculature systems support retinal development and visual function. Pathological ocular
A

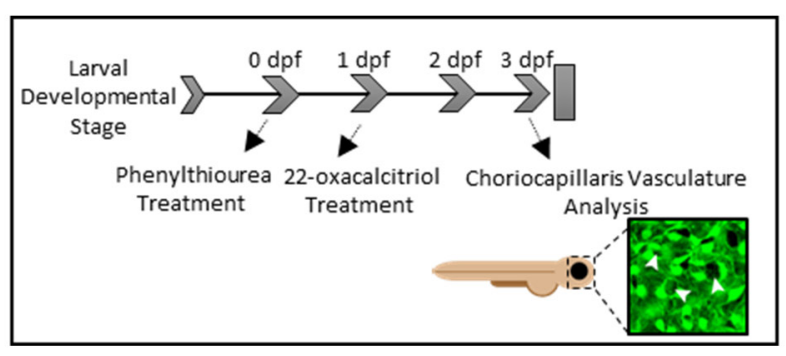

B

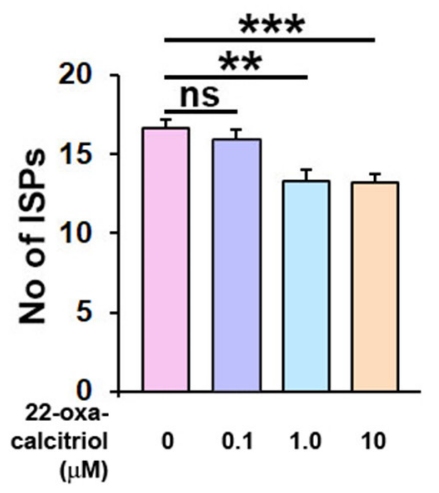

C

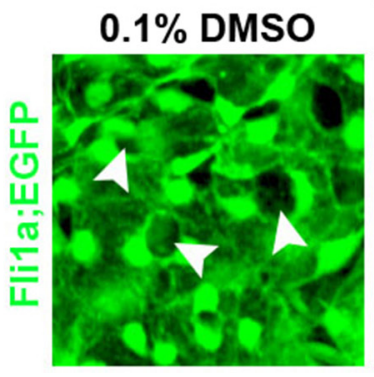

22-oxacalcitriol

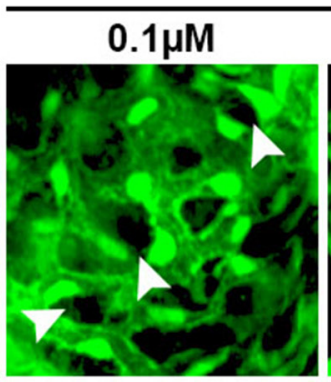

$1 \mu \mathrm{M}$

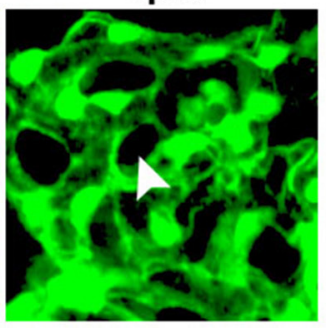

\section{$10 \mu \mathrm{M}$}

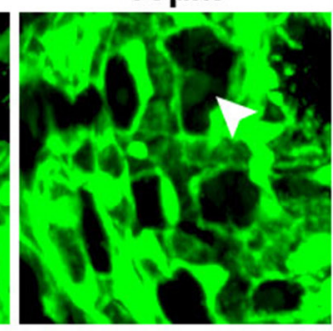

Figure 4: 22-oxacalcitriol attenuates choriocapillaris development in zebrafish larvae. (A) $\operatorname{Tg}(F l i l a: E G F P)^{\mathrm{y} 1}$ transgenic zebrafish larvae were treated with vehicle control or 22-oxacalcitriol between 24-72 hpf. (B) Graph showing number of ISPs as a measure of the extent of active vascular growth. Statistical analyses were performed using t-test; asterisk indicates ${ }^{* *} \mathrm{p} \leq 0.01$ and ${ }^{* * *} \mathrm{p} \leq 0.001$ and $\mathrm{n}=2, \mathrm{~N}=20$. ns, non-significant. (C) Representative GFP images of choriocapillaris development in zebrafish larvae treated with vehicle control or 0.1-10 $\mu \mathrm{M}$ 22-oxacalcitriol treatment. Arrowheads indicate ISPs. 
neovascularisation is a hallmark in numerous diseases causing vision loss, including nAMD. Anti-angiogenics have revolutionised nAMD treatment, yet their longterm safety profiles remain controversial and they require frequent intravitreal injection due to their molecular weights greater than $50 \mathrm{kDa}[33,34]$. Here, we investigated the anti-angiogenic activity and safety of agonists targeting the VDR, in zebrafish larvae, human cell cultures and murine models. We report four significant findings. First, we demonstrate the ex vivo ocular anti-angiogenic activity of calcitriol and 22-oxacalcitriol in a physiological mouse model of angiogenesis. Second, 22-oxacalcitriol exerts ocular anti-angiogenic activity in a zebrafish model of choroidal vasculature development. Third, calcitriol and 22-oxacalcitriol attenuate neovascularisation in an in vivo pathological mouse model with features of nAMD.
A
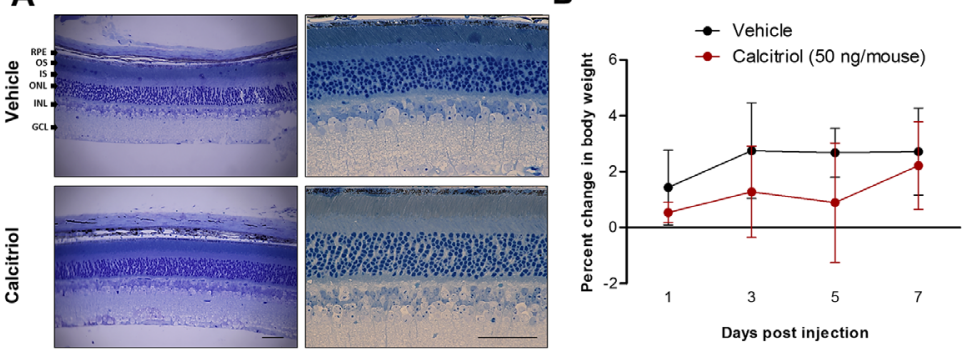

C
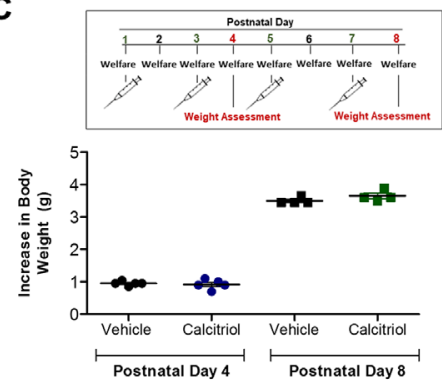

E

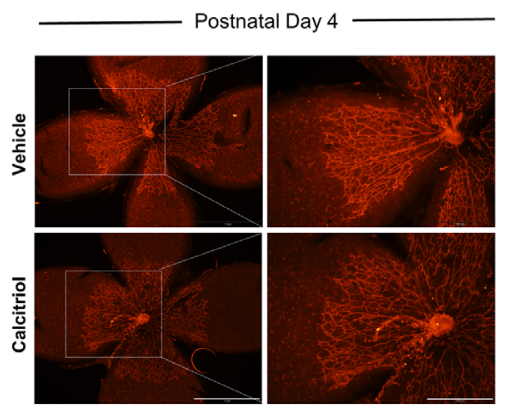

D
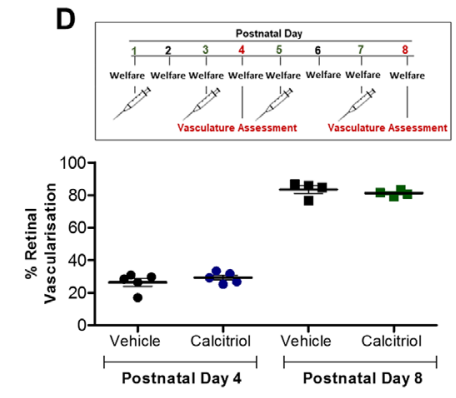

$\mathbf{F}$

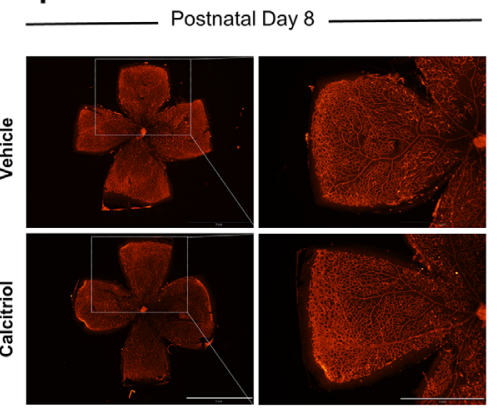

Figure 5: No ocular morphological defects were identified in mice treated with calcitriol and calcitriol treatment on alternating days does not attenuate superficial retinal vasculature development in C57BL/6J mice. (A) Toluidine blue stained ocular cross sections 7 days after vehicle or $50 \mathrm{ng}$ calcitriol treatment show an absence of gross morphological defects and the presence of normal retinal lamination in ocular sections. RPE; retinal pigmented epithelium, OS; outer segment, IS; inner segment, ONL; outer nuclear layer, INL; inner nuclear layer, GCL; ganglion cell layer. Scale bar represents $0.5 \mathrm{~mm}$. (B) Change in mouse body weight over 7 days was monitored as an indication of animal welfare. Graph shows change in body weight $(\mathrm{g}) \pm \mathrm{SEM}(\mathrm{n}=3)$ in response to vehicle control or $50 \mathrm{ng}$ calcitriol treatment. (C-F) C57BL/6J mice at P1, P3, P5 and P7 received a s.c. injection of $3.75 \mathrm{ng}$ calcitriol or vehicle control, welfare was monitored daily and superficial retinal vasculature development quantified at P4 or P8. (C) Change in mouse body weight between P1-4 or P1-8 was calculated, graph shows increase in body weight (g) from P1, \pm SEM. No significant difference in body weight between $3.75 \mathrm{ng}$ calcitriol and vehicle injected mice was identified at P4 or P8. (D) Superficial retinal vasculature area compared to retina area was calculated at $\mathrm{P} 4$ and $\mathrm{P} 8$. Scatter graph shows no significant difference between superficial retinal vasculature development at P4 or P8 between mouse pups treated with vehicle control or calcitriol. (E-F) Isolectin B4-Alexa Fluor 594 stained retinal flat-mount image representations show no difference between superficial retinal vasculature development at P4 or P8 between mouse pups treated with vehicle control or $3.75 \mathrm{ng}$ calcitriol. Scale bar represents $500 \mu \mathrm{m}$ and $1 \mathrm{~mm}$, left and right panels, respectively. 
Finally, we show 22-oxacalcitriol, a vitamin D agonist not associated with hypercalcemia, to present with an improved safety profile compared to calcitriol in human RPE cells and mice. Together this supports the potential of vitamin D agonists, particularly 22-oxacalcitriol, as anti- angiogenic agents for the treatment or prevention of ocular angiogenic disorders.

A combination of pathological changes to the photoreceptors, RPE, Bruch's membrane and choroid underpin visual impairment in nAMD. Therefore,
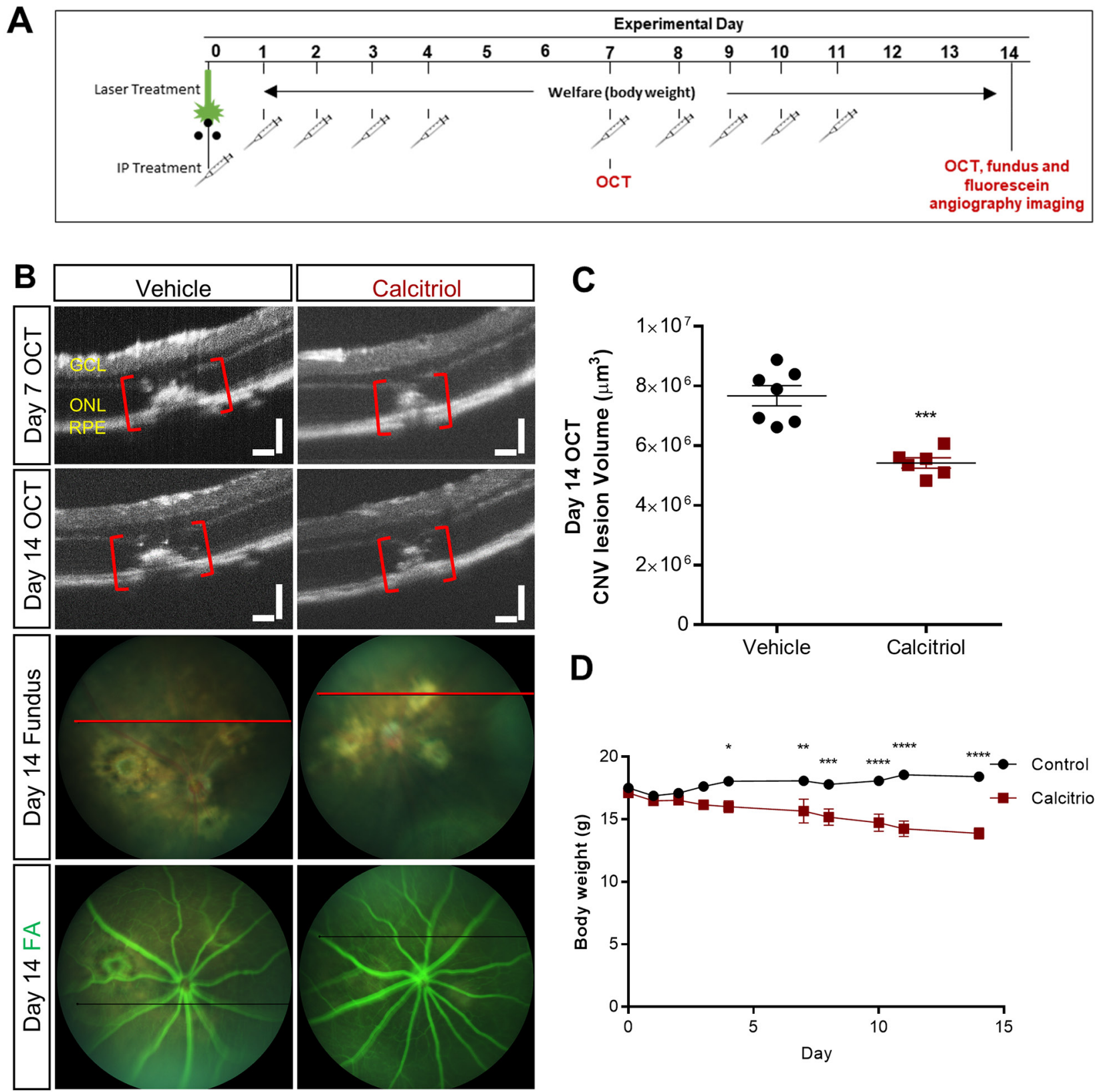

D

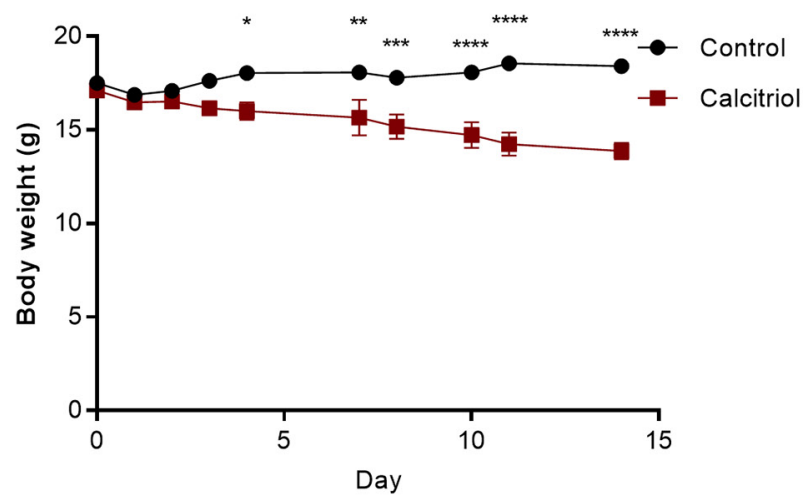

Figure 6: Effect of calcitriol on choroidal neovascularisation. (A) CNV was induced by laser on day 0 and calcitriol delivered i.p. with a 5 days on/2 days off treatment regime. OCT, fundus and/or fluorescein angiography (FA) images were acquired on day 7 and/or 14. (B) Representative OCT, fundus and FA images on day 14. GCL: ganglion cell layer, ONL: outer nuclear layer, RPE: retinal pigment epithelium. Plane of OCT images shown as a red line on brightfield fundus images. The horizontal black line in the FA images is inserted by the imaging software at the time of image capture; it shows the position of the OCT guide beam. Scale bars $=100 \mu \mathrm{m}$. (C) Quantification of the laser-induced CNV lesion volume calculated as an ellipsoid from OCT data, showing reduction in CNV lesions with calcitriol treatment on both day 7 and day 14. Calcitriol was delivered i.p. $5 \mu \mathrm{g} / \mathrm{kg}$. Vehicle was almond oil. ${ }^{* *} \mathrm{p}=0.0002$, Unpaired t-test (two tailed) with Welch's correction, Mean \pm SEM, $\mathrm{n}=6$-7 eyes. (D) Effects of calcitriol treatment on body weight. ${ }^{*} \mathrm{p}<0.05,{ }^{* *} \mathrm{p}<0.01,{ }^{* * *} \mathrm{p}<0.001$, ${ }^{* * * *} \mathrm{p}<0.0001$, two-way repeated-measures ANOVA with Holm-Sidak post hoc tests. Mean $\pm \mathrm{SEM}, \mathrm{n}=6$ animals. 
modelling such a complex disease in vitro can be challenging. The ex vivo choroidal sprouting angiogenesis model is multi-cellular, comprising of RPE cells, endothelial cells, macrophages and pericytes [25]. The choriocapillaris is the vasculature located immediately posterior to the RPE and highly sensitive to VEGF-A signalling during development and in pathologies such as AMD [1]. In initial studies, calcitriol attenuated ex vivo choroidal sprouting angiogenesis. This anti-angiogenic response is consistent with previous studies wherein

A
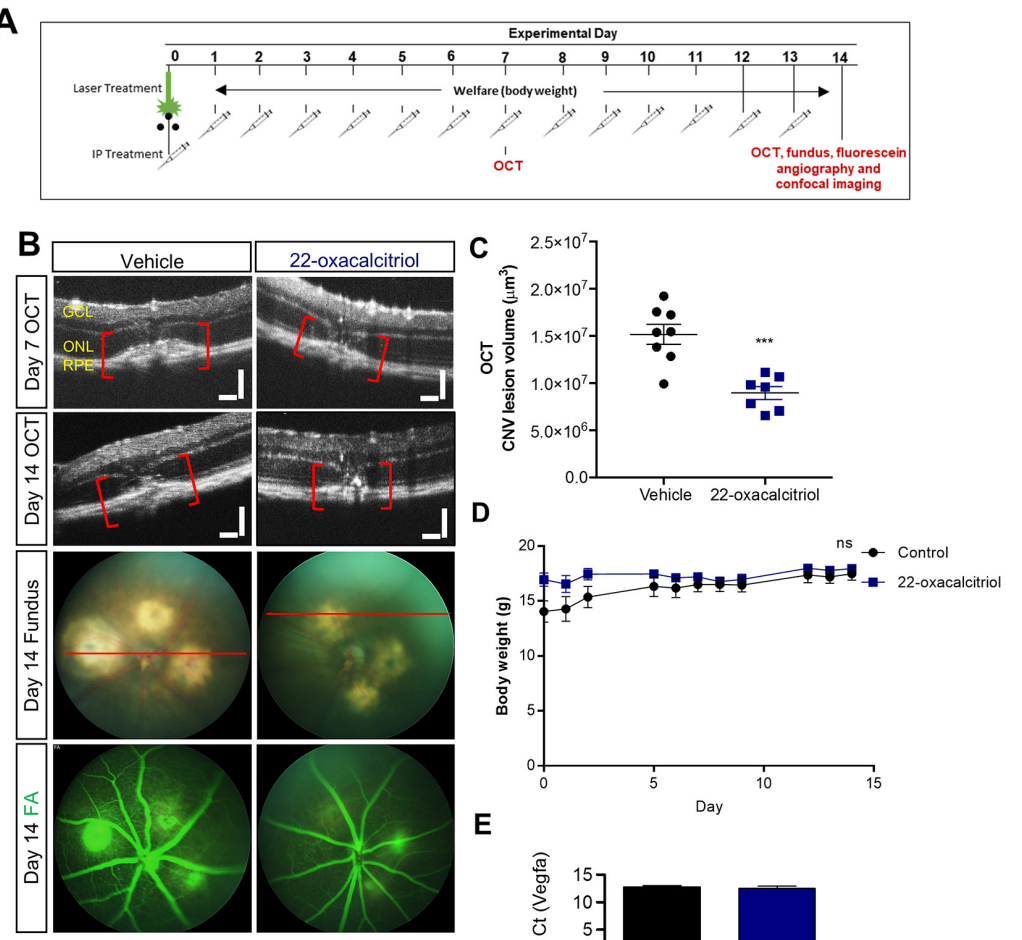

E
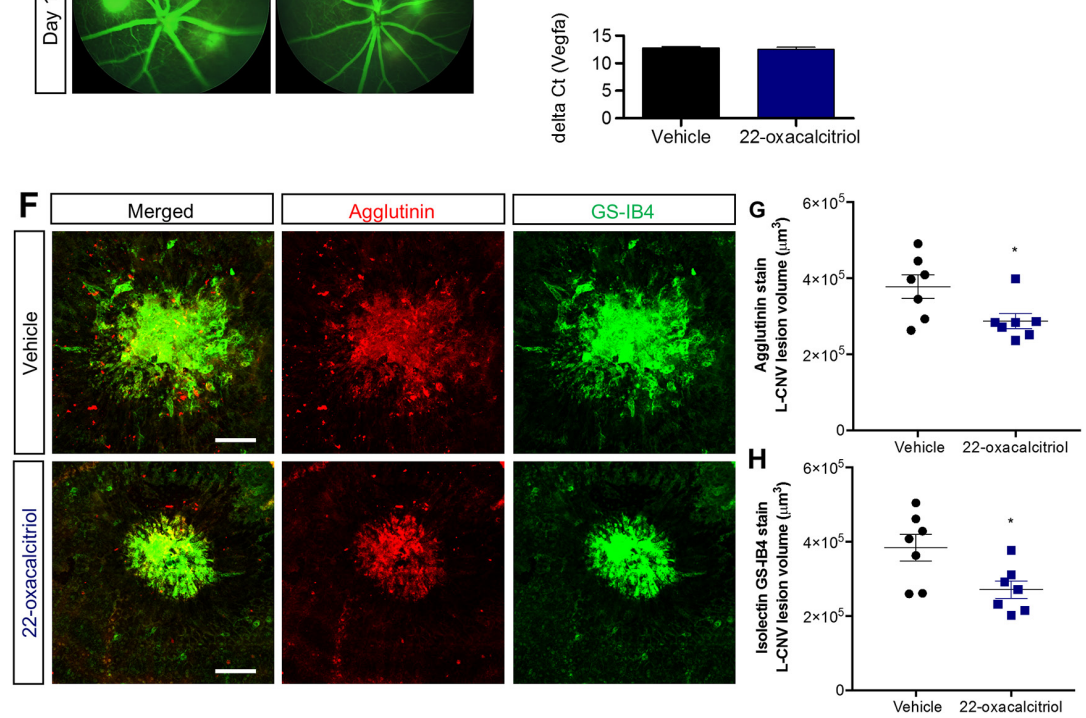

Figure 7: Effect of 22-oxacalcitriol on choroidal neovascularisation. (A) CNV was induced by laser on day 0 and $15 \mu \mathrm{g} /$ $\mathrm{kg}$ 22-oxacalcitriol delivered i.p. daily. Vehicle was $0.1 \%$ ethanol-PBS. OCT, fundus and/or FA images were acquired on day 7 and 14. (B) Representative OCT, fundus and FA images on day 14. GCL: ganglion cell layer, ONL: outer nuclear layer, RPE: retinal pigment epithelium. Plane of OCT images shown as a red line on brightfield fundus images. Scale bars $=100 \mu \mathrm{m}$. (C) Quantification of the laserinduced CNV lesion volume calculated as an ellipsoid from OCT data, showing reduction in CNV lesions with 22-oxacalcitriol treatment on both day 7 and day 14; day 14 data shown. ${ }^{* * *} \mathrm{p}=0.0003$, Unpaired t-test (two tailed) with Welch's correction, Mean $\pm \mathrm{SEM}, \mathrm{n}=7-8$ eyes. (D) Effects of 22-oxacalcitriol treatment on body weight. ns, non-significant, two-way repeated-measures ANOVA. Mean \pm SEM, $\mathrm{n}=6$ animals. (E) Vegfa mRNA expression in the mouse eye was quantified after daily 22-oxacalcitriol or vehicle control for 14 days. Vegfa expression was consistent in vehicle control and 22-oxacalcitriol treated eyes. (F) Representative images from confocal microscopy of agglutinin and GS-IB4 stained CNV lesions 14 days post L-CNV. Scale bars $=100 \mu \mathrm{m}$. (G-H) Quantification of CNV lesion volume using Z-stack confocal images. " $\mathrm{p}<0.03$, Unpaired t-test (two tailed) with Welch's correction, Mean $\pm \mathrm{SEM}, \mathrm{n}=7$ eyes. 
calcitriol inhibits angiogenesis in a chick chorioallantoic membrane (CAM) model [35], an OIR model [30] and a transgenic mouse model of retinoblastoma [35]. Interestingly, here calcitriol did not inhibit in vitro cord formation in human dermal- or retinal-derived endothelial cells. This is contrary to previous findings which demonstrated calcitriol to inhibit mouse retinal endothelial cell capillary network formation on a basement membrane [30]. Interestingly, Bao et al. reported calcitriol to exert no effect on HUVEC cord formation, yet attenuated HUVEC cord formation when stimulated with prostate cancer cell conditioned medium [36]. These differences suggest that the anti-angiogenic activity of calcitriol is context- or environmental-dependent. As the choroidal explant assay employed here is multi-cellular in nature, it is plausible that anti-angiogenic responses are not directly induced by the endothelial cells, but instead through regulation from neighbouring cells (e.g. pericytes).

Calcitriol treatment induces oedema and impairs visual function in zebrafish larvae [23]. Therefore, the safety profile of calcitriol was assessed here in a mammalian system. In mice, calcitriol treatment was well-tolerated in developing pups with no ocular morphological welfare concerns or weight loss at selected dose. We hypothesised that in vivo calcitriol would stall development of the mouse retinal vasculature, correlating with previous observations in zebrafish larvae [23]. However, mouse retinal vascular plexus development at P4 or P8 was not attenuated by $0.00375 \mu \mathrm{g}$ calcitriol subcutaneously administered as a single dose or repeatedly on alternating days. The lack of efficacy could be a consequence of suboptimal dosing or short drug half-life $\left(t_{1 / 2}\right)$ of a few hours [37]. Alternatively, lack of anti-angiogenic activity could result from poor distribution to the eye, suboptimal vehicle selection or the early developmental status of the retinal vasculature. Calcitriol in vivo was previously reported to inhibit retinal neovascularization in a pathological OIR model of retinopathy of prematurity at a concentration of $5 \mu \mathrm{g} / \mathrm{kg}$ via intraperitoneal administration daily from P12 to P17 [30]. Subsequently, we hypothesised that calcitriol may exert an anti-angiogenic effect in vivo on the choroidal vasculature, consistent with our data in the ex vivo choroidal explants. Significantly, $5 \mu \mathrm{g} / \mathrm{kg}$ calcitriol administered intraperitoneally daily attenuated L-CNV in adult mice. However, the short calcitriol $t_{1 / 2}$ suggests that frequent administration is required for chronic conditions [37]. Of further concern, the calcitrioltreated arm in the L-CNV study presented with reduced body weight, a response also reported by Albert et al. in OIR studies [30]. Weight loss in calcitriol treated animals is likely a consequence of hypercalcemia.

Vitamin D regulates calcium mobilisation, therefore high-dose vitamin D treatment can induce hypercalcemia. VDR agonists including 22-oxacalcitriol were developed to reduce calcemic responses. 22-oxacalcitriol is a calcitriol analogue with an oxygen substituted for carbon at position 22 , and is approved for the treatment of psoriasis due to its therapeutic activity and reduced calcemic responses [38]. Interestingly, 22-oxacalcitriol inhibits CAM angiogenesis in a dose-dependent manner [39]. Here calcitriol decreased ARPE-19 cell viability, a result not observed with 22-oxacalcitriol. Differing responses induced by vitamin D and analogues could be the result of altered protein binding, metabolism, receptor affinity, dimerization and co-regulator recruitment [38]. 22-oxacalcitriol is reported to have reduced vitamin D-binding protein affinity, up to 500 times lower than calcitriol [40].

22-oxacalcitriol attenuates zebrafish hyaloid vasculature development, a lens associated system which metamorphs into a retina-associated vasculature system [23, 41]. Here, 22-oxacalcitriol attenuated both ex vivo mouse microvascular sprouting in choroidal explants and choroidal vasculature development in zebrafish larvae. Thus, our revised hypothesis was that 22-oxacalcitriol can exert an anti-angiogenic effect on the choroidal vasculature in vivo without adverse effects linked to hypercalcemia. Our novel findings demonstrate that 22-oxacalcitriol exerts significant anti-angiogenic activity in the mouse L-CNV model. Importantly, weight loss did not occur in the 22-oxacalcitriol treatment arms. An advantage of 22-oxacalcitriol as a treatment for ocular disorders is, as a small molecule, vitamin D has the potential to be delivered orally. However, future studies will need to investigate the in vivo ocular pharmacokinetics and anti-angiogenic efficacy with oral administration.

Vitamin D traditionally mediates its effects through the VDR, a nuclear receptor expressed diversely throughout the body which regulates the transcription of hundreds of genes [38]. The anti-angiogenic effects of vitamin D appear VDR-dependent. First, knockout (KO) of the VDR affects tumour vasculature integrity, resulting in vessel enlargement and reduced pericyte coverage [42]. Second, increased expression of pro-angiogenic factors including VEGF have been identified in tumours from VDR KO mice [42]. Third, calcitriol attenuates oxygen-induced neovascularisation in mice, a response reduced in VDR KO mice [43]. We previously reported calcitriol treatments to regulate VEGF expression in the developing eye [23]. However, here in the L-CNV model, ocular Vegfa expression was not altered by 22-oxacalcitriol. This is in line with Albert et al. who found ocular VEGF protein expression to be comparable in calcitriol and vehicle control treated mice in the OIR model of ocular neovascularisation [30]. Angiogenesis is driven by an array of factors. Indeed, vitamin D regulates a plethora of other angiogenic factors including HIF $1 \alpha$, IL- 8 , TGF- $\beta$, bone morphogenetic protein-2A, endothelin 1, cysteinerich angiogenic inducer 6 , midkine, MMP-2 and MMP-9 $[36,44,45]$. Thus, additional studies are needed to elucidate the anti-angiogenic mechanism and VEGF dependency of responses induced by vitamin $\mathrm{D}$ in an ocular setting. 
In summary, we present original findings on the anti-angiogenic efficacy of VDR agonists in the eye using an evolutionarily diverse range of in vivo and ex vivo models. Notably, in a mouse model of pathological choroidal neovascularisation, 22-oxacalcitriol is welltolerated and significantly reduces the size of vascular lesions. This drug represents a promising therapeutic or preventative treatment for ocular angiogenic disorders associated with choroidal vasculopathies.

\section{MATERIALS AND METHODS}

\section{Ethical statement and approvals}

Approval for the use of post-mortem mouse tissue for research purposes was granted by the UCD Animal Research Ethics Committee (AREC), AREC-16-31Kennedy. Mouse developmental and safety studies were conducted with approval by the UCD AREC (AREC15-07-Kennedy) and the Health Products Regulatory Authority (AE18982/P064). Mouse L-CNV experiments followed the guidelines of the Association for Research in Vision and Ophthalmology Statement for the Use of Animals in Ophthalmic and Visual Research and were approved by the Indiana University School of Medicine Institutional Animal Care and Use Committee. Zebrafish choroidal angiogenesis studies were approved by the Linköping Animal Research Ethics Committee (N89/15). All experiments were performed in accordance with relevant guidelines and regulations.

\section{Mouse choroidal sprouting angiogenesis assay}

The mouse choroidal sprouting procedure was adapted from Shao et al. and performed as per Figure 1A [25]. C57BL/6J mice aged between 6-12 weeks were euthanised by $\mathrm{CO}_{2}$ asphyxiation, eyes immediately enucleated and placed in ice cold Endothelial Cell Growth Medium (PromoCell). Eyes were cut along the pars planar, cornea removed, lens removed, and four incisions made facilitating flattening of the eyecup. The neural retina was removed from the RPE/choroid complex and six-eight $1 \times 1 \mathrm{~mm}$ RPE-choroid explants cut from each quadrant. Explants were transferred to $30 \mu$ l thawed Matrigel ${ }^{\circledR}$ (BD Biosciences) in a 24 well plate, uniformly orientated, incubated for $20 \mathrm{~min}$ at $37^{\circ} \mathrm{C}\left(5 \% \mathrm{CO}_{2}, 95 \% \mathrm{O}_{2}\right)$ and $500 \mu \mathrm{l}$ medium applied. Following 1 day of culturing, medium was exchanged, and vehicle control, calcitriol and 22-oxacalcitriol treatments applied with a final well volume of $500 \mu \mathrm{l}$. Treatments were replenished on day 3-4. Culturing was ended on day 7 and explants were imaged immediately, calcein stained or fixed in $4 \%$ PFA overnight.

\section{Calcein staining}

Following 7 days of culturing, RPE-choroid explants were washed with phosphate-buffered saline (PBS) and
$300 \mu \mathrm{l}$ of $8 \mu \mathrm{g} / \mathrm{ml}$ Calcein AM (Thermo Fisher Scientific) applied to each explant and incubated for $1 \mathrm{~h}$ at $37^{\circ} \mathrm{C}(5 \%$ $\mathrm{CO}_{2}, 95 \% \mathrm{O}_{2}$ ). Three PBS washes were performed, and explants imaged.

\section{Image acquisition and sprouting area quantification}

Brightfield images were acquired using Olympus SZX16 or Zeiss Axiovert $200 \mathrm{M}$ microscopes with $\mathrm{Cell}^{\wedge} \mathrm{F}$ or Zeiss Axiovision image analysis software. Sprouting area and explant area were manually quantified using ImageJ freehand tool and explant area subtracted from overall area. Statistical differences between vehicleand drug-treated samples were determined by one-way ANOVA with Dunnett's post-hoc test. Statistical analyses were performed with PRISM 5 software and significance accepted where $\mathrm{P} \leq 0.05$.

\section{ARPE-19 cell MTT viability assay}

ARPE-19 cells were maintained in Dulbecco's Modified Eagle's Medium Nutrient Mixture F-12 (Sigma Aldrich) with 10\% fetal bovine serum (FBS) (Gibco), 2 $\mathrm{mM}$ L-glutamine (Gibco) and 100 units/ml penicillinstreptomycin (Gibco). Briefly, $1.4 \times 10^{4}$ cells were applied per well of a 96 well plate and incubated at $37^{\circ} \mathrm{C}(5 \%$ $\mathrm{CO}_{2}, 95 \% \mathrm{O}_{2}$ ) overnight in complete medium. Complete medium was replaced with FBS-negative medium and plates incubated overnight at $37^{\circ} \mathrm{C}\left(5 \% \mathrm{CO}_{2}, 95 \% \mathrm{O}_{2}\right)$. FBS-negative medium was replaced with treatments in FBS-negative medium at indicated concentrations, with 4 replicate wells per treatment and incubated at $37^{\circ} \mathrm{C}(5 \%$ $\mathrm{CO}_{2}, 95 \% \mathrm{O}_{2}$ ). At the desired treatment end-point $10 \mu \mathrm{l}$ of $5 \mathrm{mg} / \mathrm{ml}$ MTT labelling Reagent (Roche) was applied per well and plates incubated at $37^{\circ} \mathrm{C}\left(5 \% \mathrm{CO}_{2}, 95 \% \mathrm{O}_{2}\right)$ for $2 \mathrm{~h} .100 \mu \mathrm{l}$ solubilisation solution (Roche) was applied per well and plates incubated at $37^{\circ} \mathrm{C}\left(5 \% \mathrm{CO}_{2}, 95 \% \mathrm{O}_{2}\right)$ for $4 \mathrm{~h}$ and absorbance read at $570 \mathrm{~nm}$ (microplate reader, $\mathrm{mtx}$ lab systems). Statistical differences between vehicleand drug-treated samples were determined by one-way ANOVA with Dunnett's post-hoc test. Statistical analyses were performed with PRISM 5 software and significance accepted where $\mathrm{P} \leq 0.05$.

\section{Choriocapillaris development assay in zebrafish}

Fertilised $\operatorname{Tg}(\text { Flila:EGFP })^{\mathrm{y} 1}$ transgenic zebrafish eggs were incubated in Phenylthiourea -containing E3medium for $24 \mathrm{~h}$ and then treated with $0.1 \%$ DMSO (vehicle control) or 22-oxacalcitriol (Cayman Chemicals) at $0.1,1.0$ or $10 \mu \mathrm{M}$ for an additional $48 \mathrm{~h}$. The larvae were then anesthetised with $0.04 \%$ MS-222 (Ethyl 3-aminobenzoate methane sulfonic acid salt 98\%, Sigma Aldrich) and fixed in 4\% PFA (Sigma Aldrich) for 30 min at room temperature. The eyes were removed and dissected using watchmakers' forceps (Dumont \#5) under a dissection microscope (Nikon SMZ 1500). The eyes were flat-mounted on glass slides in Vectashield mounting medium (H-1000 Vector laboratories) and imaged by 
confocal microscopy (Zeiss, LSM 700). The number of ISPs were counted manually and used as a measure of the extent of active vascular growth.

Calcitriol tolerance study in adult mice: Weight and retina histology

Calcitriol (Selleckchem) was dissolved to $1 \mathrm{mg} /$ $\mathrm{ml}$ in ethanol and working dilutions to $1 \mu \mathrm{g} / \mathrm{ml}$ in PBS prepared. Male C57BL/6J mice between 3-6 months were subcutaneously (s.c.) administered $50 \mathrm{ng}$ calcitriol or vehicle control and animal weight recorded daily over a 7 day period.

On day 7, mice were euthanised by $\mathrm{CO}_{2}$ asphyxiation, eyes enucleated, bisected and fixed with 2.5\%: 2\% glutaraldehyde: PFA in $0.1 \mathrm{M}$ Sorenson phosphate buffer (SPB) (pH 7.3). Fixed eyes were washed in $0.1 \mathrm{M} \mathrm{SPB}$ and transferred to $1 \%$ osmium tetroxide in $0.2 \mathrm{M} \mathrm{SPB}$ for $1 \mathrm{~h}$ at room temperature. Eyes were exposed to an ethanol gradient; $30 \%, 50 \%, 70 \%, 90 \%$ for $10 \mathrm{~min}$ each; $100 \%$ for $1 \mathrm{~h}$ and acetone for $30 \mathrm{~min}$. Eyes were uniformly positioned within an Epon resin primed mould, mould levelled with Epon resin composed of agar 100 resin, dodecenyl succinic anhydride, methyl nadic anhydride and 2,4,6-tris (dimethylaminomethyl) (Agar Scientific) and incubated overnight at $50^{\circ} \mathrm{C}$. Ultrathin ocular cross sections, $1 \mu \mathrm{m}$, were acquired using a diamond knife and Leica EM UC6 microtome. Sections were toluidine blue stained, cover-slipped (DPX mounting medium) and representative images acquired (Nikon Eclipse E80i Microscope, Canon camera). Mouse retina morphology between vehicle control and calcitriol treated samples were compared to identify deviations in retina cell organisation, retinal thickness and pyknotic nuclei presence.

\section{Mouse model of retinal vasculature development}

Experimental design followed Yagasaki et al [46]. Dams along with their pups were raised in standard light (12 $\mathrm{h}$ light and $12 \mathrm{~h}$ dark cycle) and standard air conditions for the duration of the study.

\section{Calcitriol dosing}

Calcitriol was prepared as previously reported [47]. Calcitriol (Selleckchem) was dissolved to $1 \mathrm{mg} / \mathrm{ml}$ in ethanol and working dilutions of $1 \mu \mathrm{g} / \mathrm{ml}$ in PBS were prepared. Calcitriol multiple injection study: Pups received a $3.75 \mathrm{ng}$ calcitriol or vehicle control s.c. treatment on P1, P3, P5 and P7. The subcutaneous route was chosen due to a greater technical compatibility to administer drugs in postnatal pups. Animal welfare was monitored daily until P4 or P8. On P4 and P8, mouse pups were euthanised by cervical dislocation, eyes immediately enucleated and fixed with $4 \%$ PFA overnight at $4{ }^{\circ} \mathrm{C}$.

\section{Retina flat-mounts}

Fixed eyes were positioned on a made-for-purpose indented dental wax strip, in PBS under a dissecting microscope. The eye was gripped at the optic nerve with a Dumont \#5 forceps and excess exterior muscle removed using a springbow microdissection scissors. The optic nerve was removed, the eye was pierced along the pars planar, the anterior eye removed using a springbow dissection scissors and lens removed. The remaining eyecup was transferred to a glass slide and 4 incisions made $2 \mathrm{~mm}$ from the site of the optic nerve with a no. 11 scalpel blade dividing the retina into 4 quadrants. Using a no. 11 blade the periphery of the quadrants were cut, straightening the outer edge and preventing curling of the retina. Retinal flat-mounts were stored in perm/block buffer composed of PBS with $0.5 \%$ Triton-X100, 1\% goat serum, and $0.1 \mathrm{mM} \mathrm{CaCl}_{2}$ (Sigma-Aldrich).

\section{Isolectin staining}

Isolectin staining was performed as previously reported [48]. Retina flat-mounts underwent permeabilisation with perm/block buffer overnight at $4^{\circ} \mathrm{C}$. Perm/block buffer was replaced with $20 \mu \mathrm{g} / \mathrm{ml} \mathrm{GS}$ isolectin B4 (Thermo Fisher Scientific) in perm/block buffer and incubated overnight at $4^{\circ} \mathrm{C}$. Flat-mounts underwent 8 perm/block buffer washes over $4 \mathrm{~h}$ at $37^{\circ} \mathrm{C}$ with 30 min interval changes. Flat-mounts were stained with Alexa-streptavidin-564 (ThermoFisher Scientific) diluted in perm/block buffer 1:500 overnight at $4^{\circ} \mathrm{C}$. Flatmounts underwent 8 perm/block buffer washes over $4 \mathrm{~h}$ at $37^{\circ} \mathrm{C}$ with $30 \mathrm{~min}$ interval changes. Flat-mounts were stored in PBS with $0.1 \mathrm{mM} \mathrm{CaCl}$. Flat-mounts were transferred to a glass slide, the retina cover-slipped with Aqua-Poly mount (Polyscience Inc) and stored protected from light at $4{ }^{\circ} \mathrm{C}$.

\section{Flat-mount image acquisition and retinal vasculature area quantification}

Fluorescent images were acquired using a Zeiss AxioVert 200M fluorescent microscope, Andor IQ2 software with Andor montaging or Olympus SZX16 fluorescence microscope with $\mathrm{Cell}^{\wedge} \mathrm{F}$ software. Retinal superficial vasculature development was expressed as vasculature area compared to total flat-mount area. Area measurements were performed using ImageJ software freehand tool.

\section{Mouse model of laser-induced choroidal neovascu- larisation}

Wild-type female C57BL/6J mice, 6-8 weeks of age, were purchased from the Jackson Laboratory (Bar Harbor, ME), and housed under standard conditions [49]. Intraperitoneal injections (i.p.) of $60 \mathrm{mg} / \mathrm{kg}$ ketamine hydrochloride and $2.5 \mathrm{mg} / \mathrm{kg}$ xylazine mixture were used for anaesthesia, and isoflurane overdose for euthanasia. Body weights were determined daily. All analyses were performed by a masked investigator.

\section{Calcitriol dosing}

Calcitriol (1000 ng/ml in almond oil; Professional Compounding Centers of America, Houston, TX) was 
purchased from Indiana School of Medicine Laboratory Animal Resource Center's drug distribution center. Each mouse received once-daily i.p. injections of $5 \mu \mathrm{g} / \mathrm{kg}$ calcitriol or almond oil vehicle for 14 days ( 5 days on/2 days off). The dose was determined based on published observations [30].

\section{2-oxacalcitriol dosing}

Pure crystalline solid 22-oxacalcitriol (Cayman Chemical, Ann Arbor, MI) was dissolved in ethanol as previously reported to yield a $2 \mu \mathrm{g} / \mu 1$ stock solution [50, 51]. This stock solution was diluted in PBS to working solution, $2 \mu \mathrm{g} / \mathrm{ml} 22$-oxacalcitriol in $0.1 \%$ ethanol-PBS on day of the injection. Each mouse in the treatment group received once-daily i.p. injections of $15 \mu \mathrm{g} / \mathrm{kg}$ 22-oxacalcitriol or ethanol-PBS vehicle every day for 14 days.

\section{Laser-induced choroidal neovascularisation}

The L-CNV mouse model was performed as previously described [52]. Briefly, both eyes of 6-8 week old $\mathrm{C} 57 \mathrm{BL} / 6 \mathrm{~J}$ mice were dilated using tropicamide, and subjected to laser treatment using $50 \mu \mathrm{m}$ spot size, $50 \mathrm{~ms}$ duration and $250 \mathrm{mV}$ pulses of an ophthalmic argon green laser wavelength $532 \mathrm{~nm}$, coupled to a slit lamp. Three laser burns per eye were created around the optic nerve at 12, 3 and 9 o' clock positions. OCT was performed in L-CNV mice as described previously [52], on days 7 and 14 post laser, using a Micron III intraocular imaging system (Phoenix Research Labs, Pleasanton, CA, USA). Briefly, eyes of anesthetised mice were dilated with $1 \%$ tropicamide solution (Alcon, Fort Worth, TX, USA) and lubricated with Gonak hypromellose ophthalmic solution (Akorn, Lake Forest, IL, USA). Horizontal and vertical OCT images were taken per lesion and L-CNV lesion volumes were obtained using the quantification method previously established $[52,53]$. To assess vascular leakage, FA was performed on day 14 post L-CNV by i.p. injection of $50 \mu \mathrm{l}$ of $25 \%$ fluorescein sodium (Fisher Scientific, Pittsburgh, PA, USA). Fundus images were taken using the Micron III system and Streampix software.

\section{Choroidal flat-mounts}

Mouse eyes were harvested on day 14 post L-CNV induction. The eyes were enucleated and fixed in 4\% PFA in PBS for $1 \mathrm{~h}$ at $4^{\circ} \mathrm{C}$. The anterior portion including lens and the retina were removed, then the posterior eyecups were dissected out and underwent further fixation in 4\% PFA in PBS overnight. The fixed eye cups were washed in blocking buffer $(0.3 \%$ Triton X-100, $5 \%$ bovine serum albumin (BSA) in PBS) for $2 \mathrm{~h}$ at $4^{\circ} \mathrm{C}$. The eye cups were then stained for vasculature using the rhodamine-labeled Ricinus communis agglutinin I (Vector Labs, Burlingame, CA, USA) and Alexa Fluor 488 conjugated-Isolectin B4 from Griffonia simplicifolia (GS-IB4) (Molecular Probes, Thermo Fisher Scientific) at 1:250 dilution in buffer containing $0.3 \%$ Triton
$\mathrm{X}-100,0.5 \% \mathrm{BSA}$ in PBS, overnight at $4^{\circ} \mathrm{C}$. The posterior eyecups were washed three times with PBS and mounted in fluorescent mounting medium (VectaShield; Vector Laboratories, Inc.) and cover-slipped. Confocal imaging and analysis of L-CNV lesion volume were performed as previously described [53]. Treatments were compared by unpaired t-test (two tailed) with Welch's correction, while mouse body weights were compared by two-way repeatedmeasures ANOVA with Holm-Sidak post hoc tests using GraphPad Prism v. 6.

\section{Mouse eye RNA extraction, cDNA synthesis and QRT- PCR}

Mouse eyes were harvested on day 14 post $\mathrm{L}-\mathrm{CNV}$ induction, lens and cornea removed and eye stored in RNAlater. Total ocular RNA was extracted using mirVana ${ }^{\mathrm{TM}}$ miRNA Isolation Kit (Thermo Fisher Scientific) as per the manufacturer's instructions. cDNA synthesis was carried out using VILO cDNA Synthesis Kit (Thermo Fisher Scientific) as per the manufacturer's instructions. QRT-PCR reactions: $0.5 \mu 1$ Taqman specific probe, $5 \mu \mathrm{l}$ TaqMan Gene Expression Master Mix, $2.5 \mu \mathrm{l}$ RNAse-free water and $2 \mu \mathrm{cDNA}$ template were made up on ice. QRT-PCR cycles were carried out with a QuantStudio 7 Flex Real-Time PCR System with QuantStudio ${ }^{\mathrm{TM}}$ Software and the following conditions applied: $50^{\circ} \mathrm{C}$ for $2 \mathrm{~min}, 95^{\circ} \mathrm{C}$ for $10 \mathrm{~min}, 95^{\circ} \mathrm{C}$ for $15 \mathrm{~s}$ with 40 repeats and $60^{\circ} \mathrm{C}$ for $1 \mathrm{~min}$.

\section{Abbreviations}

nAMD: Neovascular Age-Related Macular Degeneration; RPE: Retinal Pigmented Epit-helium; VEGF: Vascular Endothelial Growth Factor; Ang: Angiopoietin; PDGF: Platelet-Derived Growth Factor; TGF: Transforming Growth Factor; VDR: Vitamin D Receptor; HREC: Human Retinal-Derived Microvascular Endothelial Cells; ISP: Interstitial Pillars; OIR: Oxygen Induced Retinopathy; L-CNV: Laser-Induced Choroidal Neovascularisation Model; OCT: Optical Coherence Tomography; CAM: Chorioallantoic Membrane; $t_{1 / 2}$ : Half-Life; AREC: Animal Research Ethics Committee; PBS: Phosphate-Buffered Saline; FBS: Fetal Bovine Serum; s.c.: Subcutaneous; SPB: Sorenson Phosphate Buffer; i.p.: Intraperitoneal; BSA: Bovine Serum Albumin; FA: Fluorescein Angiography; KO: Knockout; hpv: hours post fertilisation (hpf).

\section{Author contributions}

\section{Author Contribution statement:}

Merrigan SL performed and analysed mouse choroidal sprouting angiogenesis assays, in vitro assays and mouse models of retinal vasculature development. Ali $\mathrm{Z}$ and Jensen LD performed and analysed choriocapillaris development assays in zebrafish. Park B and Corson TW 
performed and analysed mouse models of laser-induced choroidal neovascularisation. Supervision, resources, experimental designs and result interpretations were carried out by Kennedy BN. Kennedy BN and Merrigan SL drafted manuscript with input from Park B, Ali Z, Jensen LD and Corson TW.

\section{ACKNOWLEDGMENTS}

The authors would like to thank the UCD Conway Institute genomics facility and imaging facility for technical support.

\section{CONFLICTS OF INTEREST}

No conflicting interest.

\section{FUNDING}

This work was supported by:

Health Research Board, HRB-POR-2013-390, Irish Research Council, GOIPG/2015/2061, NIH/ NEI R01EY025641, Retina Research Foundation, The foundation Jeanssons Stiftelser, The Magnus Bergvall foundation, and The Swedish Eye foundation.

\section{REFERENCES}

1. Jager RD, Mieler WF, Miller JW. Age-related macular degeneration. $\mathrm{N}$ Engl J Med. 2008; 358:2606-17. https://doi.org/10.1056/NEJMra0801537. [PubMed]

2. Wong WL, Su X, Li X, Cheung CM, Klein R, Cheng CY, Wong TY. Global prevalence of age-related macular degeneration and disease burden projection for 2020 and 2040: a systematic review and metaanalysis. Lancet Glob Health. 2014; 2:e106-16. https://doi.org/10.1016/s2214-109x(13)70145-1. [PubMed]

3. Sarwar S, Clearfield E, Soliman MK, Sadiq MA, Baldwin AJ, Hanout M, Agarwal A, Sepah YJ, Do DV, Nguyen QD. Aflibercept for neovascular age-related macular degeneration. Cochrane Database Syst Rev. 2016; 2:CD011346. https://doi.org/10.1002/14651858.CD011346.pub2. [PubMed]

4. Topal T, Kar T, Yildirim Y, Sagdic SK, Buyukavsar C, Kaya A, Ayata A, Sonmez M, Unal MH. Evaluation of aflibercept treatment responses in eyes with bevacizumab/ ranibizumab-resistant wet age-related macular degeneration. Turk J Ophthalmol. 2017; 47:133-7. https://doi.org/10.4274/tjo.34735. [PubMed]

5. Campochiaro PA. Ocular neovascularization. J Mol Med (Berl). 2013; 91:311-21. https://doi.org/10.1007/s00109-013-0993-5. [PubMed]

6. Saint-Geniez M, D'Amore PA. Development and pathology of the hyaloid, choroidal and retinal vasculature. Int $\mathrm{J}$ Dev Biol. 2004; 48:1045-58. https://doi.org/10.1387/ijdb.041895ms. [PubMed]

7. Holz FG, Schmitz-Valckenberg S, Fleckenstein M. Recent developments in the treatment of age-related macular degeneration. J Clin Invest. 2014; 124:1430-8. https://doi.org/10.1172/jci71029. [PubMed]

8. Das A, Stroud S, Mehta A, Rangasamy S. New treatments for diabetic retinopathy. Diabetes Obes Metab. 2015; 17:219-30. https://doi.org/10.1111/dom.12384. [PubMed]

9. Duh EJ, Sun JK, Stitt AW. Diabetic retinopathy: current understanding, mechanisms, and treatment strategies. JCI Insight. 2017; 2. https://doi.org/10.1172/jci.insight.93751. [PubMed]

10. Folkman J. Angiogenesis in cancer, vascular, rheumatoid and other disease. Nat Med. 1995; 1:27-31. https://doi.org/10.1038/nm0195-27. [PubMed]

11. Gariano RF, Gardner TW. Retinal angiogenesis in development and disease. Nature. 2005; 438:960-6. https://doi.org/10.1038/nature04482. [PubMed]

12. Kaiser PK. Emerging therapies for neovascular age-related macular degeneration: drugs in the pipeline. Ophthalmology. 2013; 120:S11-5. https://doi.org/10.1016/j.ophtha.2013.01.061. [PubMed]

13. Yang S, Zhao J, Sun X. Resistance to anti-VEGF therapy in neovascular age-related macular degeneration: a comprehensive review. Drug Des Devel Ther. 2016; 10:1857-67. https://doi.org/10.2147/dddt.s97653. [PubMed]

14. Balaratnasingam C, Dhrami-Gavazi E, McCann JT, Ghadiali Q, Freund KB. Aflibercept: a review of its use in the treatment of choroidal neovascularization due to agerelated macular degeneration. Clin Ophthalmol. 2015; 9:2355-71. https://doi.org/10.2147/opth.s80040. [PubMed]

15. Zhao Y, Singh RP. The role of anti-vascular endothelial growth factor (anti-VEGF) in the management of proliferative diabetic retinopathy. Drugs Context. 2018; 7:212532. https://doi.org/10.7573/dic.212532. [PubMed]

16. van Asten F, Michels CTJ, Hoyng CB, van der Wilt GJ, Klevering BJ, Rovers MM, Grutters JPC. The cost-effectiveness of bevacizumab, ranibizumab and aflibercept for the treatment of age-related macular degeneration-A cost-effectiveness analysis from a societal perspective. PLoS One. 2018; 13:e0197670. https://doi.org/10.1371/journal.pone.0197670. [PubMed]

17. Lux A, Llacer H, Heussen FM, Joussen AM. Nonresponders to bevacizumab (Avastin) therapy of choroidal neovascular lesions. Br J Ophthalmol. 2007; 91:1318-22. https://doi.org/10.1136/bjo.2006.113902. [PubMed]

18. Theodoratou E, Tzoulaki I, Zgaga L, Ioannidis JP. Vitamin $\mathrm{D}$ and multiple health outcomes: umbrella review of systematic reviews and meta-analyses of observational studies and randomised trials. BMJ. 2014; 348. https://doi.org/10.1136/bmj.g2035. [PubMed]

19. Chakraborti CK. Vitamin D as a promising anticancer agent. Indian J Pharmacol. 2011; 43:113-20. https://doi.org/10.4103/0253-7613.77335. [PubMed] 
20. Leyssens C, Verlinden L, Verstuyf A. The future of vitamin D analogs. Front Physiol. 2014; 5:122. https://doi.org/10.3389/fphys.2014.00122. [PubMed]

21. Feldman D, Krishnan AV, Swami S, Giovannucci E, Feldman BJ. The role of vitamin D in reducing cancer risk and progression. Nat Rev Cancer. 2014; 14:342-57. https://doi.org/10.1038/nrc3691. [PubMed]

22. Reins RY, Baidouri H, McDermott AM. Vitamin D activation and function in human corneal epithelial cells during TLR-induced inflammation. Invest Ophthalmol Vis Sci. 2015; 56:7715-27. https://doi.org/10.1167/iovs.15-17768. [PubMed]

23. Merrigan SL, Kennedy BN. Vitamin D receptor agonists regulate ocular developmental angiogenesis and modulate expression of dre-miR-21 and VEGF. Br J Pharmacol. 2017; 174:2636-2651. https://doi.org/10.1111/bph.13875. [PubMed]

24. Smith EJ, Staton CA. (2007). Tubule Formation Assays. Angiogenesis Assays (eds CA Staton, C Lewis and R Bicknell): John Wiley \& Sons), 65-87.

25. Shao Z, Friedlander M, Hurst CG, Cui Z, Pei DT, Evans LP, Juan AM, Tahiri H, Duhamel F, Chen J, Sapieha P, Chemtob $\mathrm{S}$, Joyal JS, et al. Choroid sprouting assay: an ex vivo model of microvascular angiogenesis. PLoS One. 2013; 8:e69552. https://doi.org/10.1371/journal.pone.0069552. [PubMed]

26. Chung I, Yu WD, Karpf AR, Flynn G, Bernardi RJ, Modzelewski RA, Johnson CS, Trump DL. Antiproliferative effects of calcitriol on endothelial cells derived from two different microenvironments. J Steroid Biochem Mol Biol. 2007; 103:768-70. https://doi.org/10.1016/j.jsbmb.2006.12.042. [PubMed]

27. Ruberte J, Ayuso E, Navarro M, Carretero A, Nacher V, Haurigot V, George M, Llombart C, Casellas A, Costa C, Bosch A, Bosch F. Increased ocular levels of IGF-1 in transgenic mice lead to diabeteslike eye disease. J Clin Invest. 2004; 113:1149-57. https://doi.org/10.1172/jci19478. [PubMed]

28. Stahl A, Connor KM, Sapieha P, Chen J, Dennison RJ, Krah NM, Seaward MR, Willett KL, Aderman CM, Guerin KI, Hua J, Lofqvist C, Hellstrom A, et al. The mouse retina as an angiogenesis model. Invest Ophthalmol Vis Sci. 2010; 51:2813-26. https://doi.org/10.1167/iovs.10-5176. [PubMed]

29. Ali Z, Cui D, Yang Y, Tracey-White D, VazquezRodriguez G, Moosajee M, Ju R, Li X, Cao Y, Jensen LD. Synchronized tissue-scale vasculogenesis and ubiquitous lateral sprouting underlie the unique architecture of the choriocapillaris. Dev Biol. 2019. [Epub ahead of print]. https://doi.org/10.1016/j.ydbio.2019.02.002. [PubMed]

30. Albert DM, Scheef EA, Wang S, Mehraein F, Darjatmoko SR, Sorenson CM, Sheibani N. Calcitriol is a potent inhibitor of retinal neovascularization. Invest Ophthalmol Vis Sci. 2007; 48:2327-34. https://doi.org/10.1167/iovs.06-1210. [PubMed]

31. Tebben PJ, Singh RJ, Kumar R. Vitamin D-mediated hypercalcemia: Mechanisms, diagnosis, and treatment. Endocr Rev. 2016; 37:521-47. https://doi.org/10.1210/er.2016-1070. [PubMed]

32. Brown AJ, Ritter CR, Finch JL, Morrissey J, Martin KJ, Murayama E, Nishii Y, Slatopolsky E. The noncalcemic analogue of vitamin D, 22-oxacalcitriol, suppresses parathyroid hormone synthesis and secretion. J Clin Invest. 1989; 84:728 32. https://doi.org/10.1172/jci114229. [PubMed]

33. Al-Latayfeh M, Silva PS, Sun JK, Aiello LP. Antiangiogenic therapy for ischemic retinopathies. Cold Spring Harbor Perspectives in Medicine. 2012; 2:a006411. https://doi.org/10.1101/cshperspect.a006411. [PubMed]

34. Rofagha S, Bhisitkul RB, Boyer DS, Sadda SR, Zhang K. Seven-year outcomes in ranibizumab-treated patients in ANCHOR, MARINA, and HORIZON: a multicenter cohort study (SEVEN-UP). Ophthalmology. 2013; 120:2292-9. https://doi.org/10.1016/j.ophtha.2013.03.046. [PubMed]

35. Shokravi MT, Marcus DM, Alroy J, Egan K, Saornil MA, Albert DM. Vitamin D inhibits angiogenesis in transgenic murine retinoblastoma. Invest Ophthalmol Vis Sci. 1995; 36:83-7. [PubMed]

36. Bao BY, Yao J, Lee YF. 1alpha, 25-dihydroxyvitamin D3 suppresses interleukin-8-mediated prostate cancer cell angiogenesis. Carcinogenesis. 2006; 27:1883-93. https://doi.org/10.1093/carcin/bg1041. [PubMed]

37. Brandi ML. Indications on the use of vitamin D and vitamin D metabolites in clinical phenotypes. Clin Cases Miner Bone Metab. 2010; 7:243-50. [PubMed]

38. Bikle DD. Vitamin D metabolism, mechanism of action, and clinical applications. Chem Biol. 2014; 21:319-29. https://doi.org/10.1016/j.chembiol.2013.12.016. [PubMed]

39. Oikawa T, Hirotani K, Ogasawara H, Katayama T, Nakamura O, Iwaguchi T, Hiragun A. Inhibition of angiogenesis by vitamin D3 analogues. Eur J Pharmacol. 1990; 178:247-50. https://doi.org/10.1016/0014-2999(90)90483-m. [PubMed]

40. Christakos S, Dhawan P, Verstuyf A, Verlinden L, Carmeliet G. Vitamin D: Metabolism, molecular mechanism of action, and pleiotropic effects. Physiol Rev. 2016; 96:365-408. https://doi.org/10.1152/physrev.00014.2015. [PubMed]

41. Alvarez Y, Cederlund ML, Cottell DC, Bill BR, Ekker SC, Torres-Vazquez J, Weinstein BM, Hyde DR, Vihtelic TS, Kennedy BN. Genetic determinants of hyaloid and retinal vasculature in zebrafish. BMC Dev Biol. 2007; 7:114. https://doi.org/10.1186/1471-213x-7-114. [PubMed]

42. Chung I, Han G, Seshadri M, Gillard BM, Yu WD, Foster BA, Trump DL, Johnson CS. Role of vitamin $\mathrm{D}$ receptor in the antiproliferative effects of calcitriol in tumor-derived endothelial cells and tumor angiogenesis in vivo. Cancer Res. 2009; 69:967-75. https://doi.org/10.1158/0008-5472.can-08-2307. [PubMed]

43. Jamali N, Wang S, Darjatmoko SR, Sorenson CM, Sheibani $\mathrm{N}$. Vitamin D receptor expression is essential during retinal vascular development and attenuation of neovascularization by $1,25(\mathrm{OH}) 2 \mathrm{D} 3$. PLoS One. 2017; 12:e0190131. https://doi.org/10.1371/journal.pone.0190131. [PubMed] 
44. Ben-Shoshan M, Amir S, Dang DT, Dang LH, Weisman Y, Mabjeesh NJ. 1alpha,25-dihydroxyvitamin D3 (Calcitriol) inhibits hypoxia-inducible factor-1/vascular endothelial growth factor pathway in human cancer cells. Mol Cancer Ther. 2007; 6:1433-9. https://doi.org/10.1158/1535-7163.mct-06-0677. [PubMed]

45. Nakagawa K, Sasaki Y, Kato S, Kubodera N, Okano T. 22-Oxa-1alpha,25-dihydroxyvitamin D3 inhibits metastasis and angiogenesis in lung cancer. Carcinogenesis. 2005; 26:1044-54. https://doi.org/10.1093/carcin/bgi049. [PubMed]

46. Yagasaki R, Nakahara T, Mori A, Sakamoto K, Ishii K. Effects of mTOR inhibition on normal retinal vascular development in the mouse. Exp Eye Res. 2014; 129:12734. https://doi.org/10.1016/i.exer.2014.11.005. [PubMed]

47. Swami S, Krishnan AV, Wang JY, Jensen K, Horst R, Albertelli MA, Feldman D. Dietary vitamin D(3) and 1,25-Dihydroxyvitamin $\mathrm{D}(3)$ (calcitriol) exhibit equivalent anticancer activity in mouse xenograft models of breast and prostate cancer. Endocrinology. 2012; 153:2576-87. https://doi.org/10.1210/en.2011-1600. [PubMed]

48. Reynolds AL, Alvarez Y, Sasore T, Waghorne N, Butler CT, Kilty C, Smith AJ, McVicar C, Wong VH, Galvin O, Merrigan S, Osman J, Grebnev G, et al. Phenotype-based discovery of 2-[(E)-2-(Quinolin-2-yl)vinyl]phenol as a novel regulator of ocular angiogenesis. J Biol Chem. 2016; 291:7242-55. https://doi.org/10.1074/jbc.M115.710665. [PubMed]
49. Wenzel AA, O’Hare MN, Shadmand M, Corson TW. Optical coherence tomography enables imaging of tumor initiation in the TAg-RB mouse model of retinoblastoma. Mol Vis. 2015; 21:515-22. [PubMed]

50. Yamamoto K, Iwagami M, Seki T, Kano S, Ota N, Ato M. Dual antiplasmodial activity of vitamin D3 and its analog, 22-oxacalcitriol, by direct and indirect mechanisms. Parasitol Int. 2017; 66:89-99. https://doi.org/10.1016/j.parint.2016.11.015. [PubMed]

51. Seubwai W, Wongkham C, Puapairoj A, Okada S, Wongkham S. 22-oxa-1,25-dihydroxyvitamin D3 efficiently inhibits tumor growth in inoculated mice and primary histoculture of cholangiocarcinoma. Cancer. 2010; 116:5535-43. https://doi.org/10.1002/cncr.25478. [PubMed]

52. Sulaiman RS, Quigley J, Qi X, O’Hare MN, Grant MB, Boulton ME, Corson TW. A simple optical coherence tomography quantification method for choroidal neovascularization. J Ocul Pharmacol Ther. 2015; 31:44754. https://doi.org/10.1089/jop.2015.0049. [PubMed]

53. Sulaiman RS, Merrigan S, Quigley J, Qi X, Lee B, Boulton ME, Kennedy B, Seo SY, Corson TW. A novel small molecule ameliorates ocular neovascularisation and synergises with anti-VEGF therapy. Sci Rep. 2016; 6:25509. https://doi.org/10.1038/srep25509. [PubMed] 